\title{
Kinetic Simulations of Diffusion-Controlled Phase Transformations in Cu-Based Alloys
}

\author{
Ying Tang ${ }^{\mathrm{a}^{*}}$, Qing Chen ${ }^{\mathrm{b}}$, and Anders Engström ${ }^{\mathrm{c}}$ \\ Thermo-Calc Software, Råsundavägen 18, SE - 16967 Solna, Sweden \\ ayingtang@thermocalc.se, b qing@thermocalc.se, canders@thermocalc.se
}

Keywords: Kinetics, Atomic mobility database, Diffusivities, CALPHAD approach, Cu-based alloys, Solidification, Precipitation.

\begin{abstract}
In this chapter, we present kinetic simulations of diffusion-controlled phase transformations in $\mathrm{Cu}$-based alloys by using our most recently developed atomic mobility database (MOBCU) for copper alloys. This database consists of 29 elements including most common ones for industrial copper alloys. It contains descriptions for both the liquid and Fcc_A1 phases. The database was developed through a hybrid CALPHAD approach based on experiments, first-principles calculations, and empirical rules. We demonstrate that by coupling the created mobility database with the existing compatible thermodynamic database (TCCU), all kinds of diffusivities in both solid solution and liquid phases in $\mathrm{Cu}$-based alloys can be readily calculated. Furthermore, we have applied the combination of MOBCU and TCCU to simulate diffusion-controlled phenomena, such as solidification, nucleation, growth, and coarsening of precipitates by using the kinetic modules (DICTRA and TC-PRISMA) in the Thermo-Calc software package. Many examples of simulations for different alloys are shown and compared with experimental observations. The remarkable agreements between calculation and experimental results suggest that the atomic mobilities for $\mathrm{Cu}$-based alloys have been satisfactorily described. This newly developed mobility database is expected to be continuously improved and extended in future and will provide fundamental kinetic data for computer-aided design of copper base alloys.
\end{abstract}

\section{Introduction}

Copper and copper alloys have excellent electrical and thermal conductivities, exhibit good strength and formability [1-3], and are widely used in a variety of products that enable and enhance our everyday lives. In recent years, the research and development of copper alloys for practical industrial applications have increased rapidly. In order to understand and model the behavior of existing alloys during materials processing, and accelerate the development of novel copper alloys, a more efficient and systematic approach is needed. To meet this challenge, computational methods and techniques are indispensable. Among various computational approaches, the CALPHAD (CALculation of PHAse Diagram) method [4, 5], which has been recognized as one of the most powerful tools to significantly reduce time and cost during the development of new materials, can effectively provide fundamental thermodynamic and kinetic data that are essential for materials design.

The CALPHAD approach uses a phenomenological methodology by computer coupling phase diagrams and thermochemistry to obtain a self-consistent set of parameters for describing the Gibbs energy of each phase in a multicomponent system from the descriptions of its constituent unary, binary, and ternary systems. Such approach is widely used to develop thermodynamic databases, which collects such a set of parameters in a systematic way. In the past decades, various reliable thermodynamic databases [6-9] have been established based on the CALPHAD approach. The CALPHAD-type thermodynamic databases can be used to calculate both stable or metastable phase equilibria and thermodynamic properties for multicomponent alloys, and thus provide fundamental information to materials design and development. It is known that most of microstructural changes such as phase transformations, homogenization, solidification, and sintering are also related to the diffusion behavior of the alloys in addition to the thermodynamic effects. Therefore, the diffusion 
information of the alloys plays also an important role during the processing of advanced materials. As for diffusivity modeling, establishing the so-called atomic mobility database has proven to be the most effective way.

Similar to the thermodynamic databases, the CALPHAD method can be used equally well to develop atomic mobility databases [10-14]. With an atomic mobility database combined with a compatible thermodynamic database, full matrices of various diffusion coefficients as functions of composition and temperature can be calculated. Besides, the use of coupled thermodynamic and atomic mobility databases enables the simulation of many metallurgical processes, ranging from solidification, homogenization, to precipitation hardening. These phase evolution behavior predictions then allow microstructure induced effects on alloy performance to be predicted. Such kinds of simulations make it possible to optimize alloy compositions and predict optimal solidification processes and solution heat treatment temperature ranges without performing many time-consuming and costly experiments.

The accuracy of the predictions is highly dependent on the quality of the thermodynamic and atomic mobility databases that are used. Most recently, a reliable thermodynamic database for copper-based alloys (TCCU) has been established [15] by the present authors via a hybrid CALPHAD approach that takes into account of various data from experiments, first-principles calculations and empirical estimations. TCCU has been developed in a 29 -element framework, and includes 123 assessed binary and 48 ternary systems, most of which are well described to their full ranges of composition and temperature. With this thermodynamics database, various phase diagrams and thermodynamic properties for different copper alloys can be calculated. Moreover, molar volume data is also incorporated in TCCU. As a result, the density, coefficient of thermal expansion, and lattice parameter of copper alloys can also be predicted. Last but not least, the TCCU database allows us to calculate thermodynamic driving forces for phase transformations and thermodynamic factors for diffusivity modeling, which makes computational kinetics possible in multicomponent systems.

In this chapter, we introduce the development of an atomic mobility database, MOBCU, intended for use in combination with TCCU for copper-based alloys. To our knowledge, MOBCU is the first atomic mobility database targeted specifically at copper alloys. We show the verification of this database by calculating various diffusivities in ternary and higher order systems against experimental data. We validate the database by performing diffusion couple simulations and make comparisons to measured composition profiles. The main objective of this chapter is to simulate kinetic reactions during solidification and subsequent heat treatment processes for typical industrial copper alloys with use of the MOBCU and TCCU databases and the Diffusion Module and Precipitation Module [16-19] in the Thermo-Calc software package.

\section{Database Development and Software Introduction}

Database Overview. MOBCU is an atomic mobility database for copper-based alloys, which includes the liquid and Fcc_A1 phases and contains 29 elements: $\mathrm{Cu}, \mathrm{Ag}, \mathrm{Al}, \mathrm{As}, \mathrm{Au}, \mathrm{B}, \mathrm{Be}, \mathrm{Bi}, \mathrm{C}$, $\mathrm{Ca}, \mathrm{Cd}, \mathrm{Co}, \mathrm{Cr}, \mathrm{Fe}, \mathrm{Mg}, \mathrm{Mn}, \mathrm{Mo}, \mathrm{Nb}, \mathrm{Ni}, \mathrm{O}, \mathrm{P}, \mathrm{Pb}, \mathrm{Pt}, \mathrm{Se}, \mathrm{Si}, \mathrm{Sn}, \mathrm{Ti}, \mathrm{Zn}$ and $\mathrm{Zr}$. MOBCU contains critically assessed self- and impurity diffusion data for the elements in the liquid and Fcc_A1 phases. Complete and critical assessments for 36 binary, 26 ternary, and 1 quaternary systems have been included for the Fcc_A1 phase. Besides, 12 binary liquid alloy systems have also been assessed. The assessed systems are summarized in Table 1. This database will be further improved when more experimental data become available. It should be noted that apart from the liquid and Fcc_A1 phases, other phases may also be included in a diffusion simulation but can be treated only as no-diffusion ones. This simplification may work out well in many practical situations if the diffusivities in the other phases are relatively small.

Development Strategy. In the first step, the experimental and theoretically predicted self-diffusion, impurity diffusion, interdiffusion and tracer diffusion coefficients of the Fcc_A1 and liquid phases in the literature are critically reviewed and analyzed. Then, the atomic mobility parameters for the liquid and Fcc_A1 phases are assessed by means of the PARROT module inside DICTRA [16, 17] based on 
the selected experimental and theoretically predicted diffusion data. During the assessment, the self-diffusion coefficients and impurity diffusion coefficients are evaluated to obtain the mobility end-members; and the intrinsic diffusion coefficients and interdiffusion coefficients are taken into consideration to introduce the interaction parameters in the binary and ternary systems. Finally, the computational simulations of compositional profiles in diffusion couples are conducted to validate the obtained mobility parameters. The critically assessed thermodynamic descriptions [15] provide reliable thermodynamic factors for the present evaluation of atomic mobilities. It should be noted that such strategy is only suitable for those systems with sufficient diffusion data. Figure 1 shows the schematic diagram for the development of MOBCU.

Table 1 List of the assessed systems in MOBCU.

\begin{tabular}{|c|c|c|c|c|c|}
\hline \multicolumn{6}{|c|}{ Fcc_A1 (36 binary, 26 ternary, and 1 quaternary systems) } \\
\hline Ag-Al & $\mathrm{Ag}-\mathrm{Au}$ & $\mathrm{Ag}-\mathrm{Cu}$ & $\mathrm{Ag}-\mathrm{Sn}$ & $\mathrm{Au}-\mathrm{Cu}$ & $\mathrm{Al}-\mathrm{Cr}$ \\
\hline $\mathrm{Al}-\mathrm{Cu}$ & $\mathrm{Al}-\mathrm{Fe}$ & $\mathrm{Al}-\mathrm{Mg}$ & Al-Mn & Al-Ni & Al-Pt \\
\hline Al-Si & Al-Ti & $\mathrm{Al}-\mathrm{Zn}$ & $\mathrm{Cr}-\mathrm{Fe}$ & $\mathrm{Cr}-\mathrm{Ni}$ & $\mathrm{Co}-\mathrm{Cu}$ \\
\hline $\mathrm{Co}-\mathrm{Fe}$ & $\mathrm{Co}-\mathrm{Ni}$ & $\mathrm{Co}-\mathrm{Pt}$ & $\mathrm{Cu}-\mathrm{Fe}$ & $\mathrm{Cu}-\mathrm{Mg}$ & $\mathrm{Cu}-\mathrm{Mn}$ \\
\hline $\mathrm{Cu}-\mathrm{Ni}$ & $\mathrm{Cu}-\mathrm{Si}$ & $\mathrm{Cu}-\mathrm{Sn}$ & $\mathrm{Cu}-\mathrm{Zn}$ & $\mathrm{Fe}-\mathrm{Mn}$ & $\mathrm{Fe}-\mathrm{Ni}$ \\
\hline $\mathrm{Mn}-\mathrm{Ni}$ & $\mathrm{Mn}-\mathrm{Zn}$ & $\mathrm{Ni}-\mathrm{Pt}$ & $\mathrm{Ni}-\mathrm{Si}$ & $\mathrm{Ni}-\mathrm{Ti}$ & $\mathrm{Ni}-\mathrm{Zn}$ \\
\hline $\mathrm{Ag}-\mathrm{Al}-\mathrm{Cu}$ & $\mathrm{Ag}-\mathrm{Au}-\mathrm{Cu}$ & $\mathrm{Al}-\mathrm{Cr}-\mathrm{Ni}$ & $\mathrm{Al}-\mathrm{Cu}-\mathrm{Fe}$ & $\mathrm{Al}-\mathrm{Cu}-\mathrm{Mg}$ & $\mathrm{Al}-\mathrm{Cu}-\mathrm{Mn}$ \\
\hline $\mathrm{Al}-\mathrm{Cu}-\mathrm{Ni}$ & $\mathrm{Al}-\mathrm{Cu}-\mathrm{Si}$ & $\mathrm{Al}-\mathrm{Cu}-\mathrm{Zn}$ & Al-Mn-Ni & Al-Ni-Pt & Al-Ni-Ti \\
\hline $\mathrm{C}-\mathrm{Cr}-\mathrm{Fe}$ & $\mathrm{C}-\mathrm{Cr}-\mathrm{Ni}$ & $\mathrm{C}-\mathrm{Fe}-\mathrm{Ni}$ & $\mathrm{Co}-\mathrm{Cu}-\mathrm{Ni}$ & $\mathrm{Cr}-\mathrm{Cu}-\mathrm{Ni}$ & $\mathrm{Cr}-\mathrm{Fe}-\mathrm{Ni}$ \\
\hline Co-Fe-Ni & $\mathrm{Cu}-\mathrm{Fe}-\mathrm{Mn}$ & $\mathrm{Cu}-\mathrm{Fe}-\mathrm{Ni}$ & $\mathrm{Cu}-\mathrm{Mn}-\mathrm{Zn}$ & $\mathrm{Cu}-\mathrm{Mn}-\mathrm{Ni}$ & $\mathrm{Cu}-\mathrm{Ni}-\mathrm{Si}$ \\
\hline $\mathrm{Cu}-\mathrm{Ni}-\mathrm{Zn}$ & $\mathrm{Cu}-\mathrm{Sn}-\mathrm{Zn}$ & $\mathrm{Cu}-\mathrm{Mn}-\mathrm{N}$ & & & \\
\hline \multicolumn{6}{|c|}{ Liquid (12 binary systems) } \\
\hline $\mathrm{Ag}-\mathrm{Cu}$ & $\mathrm{Ag}-\mathrm{Sn}$ & $\mathrm{Al}-\mathrm{Cu}$ & $\mathrm{Al}-\mathrm{Si}$ & Al-Mg & Al-Ni \\
\hline $\mathrm{Al}-\mathrm{Zn}$ & $\mathrm{Cu}-\mathrm{Sn}$ & $\mathrm{Fe}-\mathrm{Mn}$ & $\mathrm{Fe}-\mathrm{Si}$ & $\mathrm{Ni}-\mathrm{Si}$ & $\mathrm{Pb}-\mathrm{Sn}$ \\
\hline
\end{tabular}

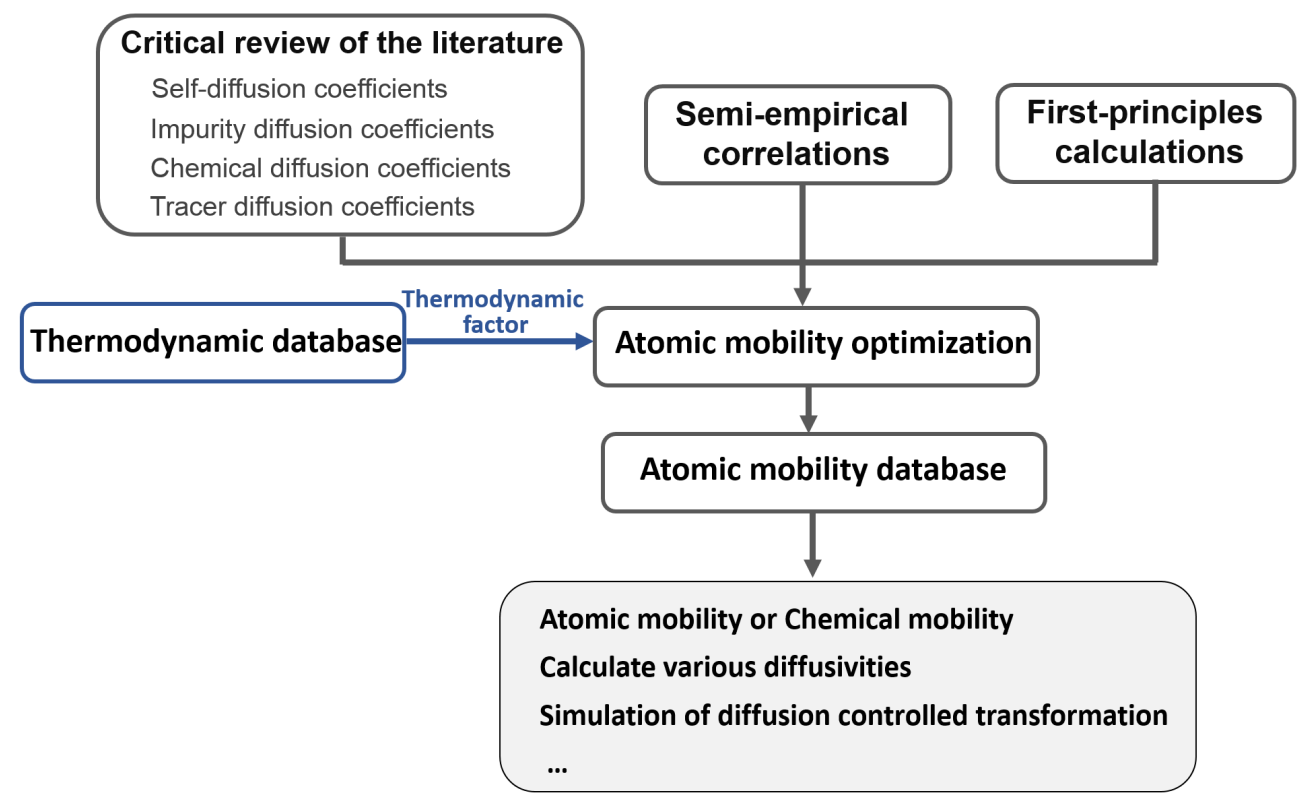

Figure 1 The schematic diagram for the development of MOBCU.

It is known that the reported diffusion data for the liquid phase is very limited due to the difficulties of the experiments. In general, an assumption that the liquid diffusion coefficient is $1 \times 10^{-9} \mathrm{~m}^{2} \mathrm{~s}^{-1}$ is made when the experimental data is not available. In this case, the calculated diffusivity in the liquid state is independent of temperature and concentration. However, the recent research work [20-26] has demonstrated that accurate liquid diffusivity data is the prerequisite for a quantitative simulation of microstructural evolution during solidification. Therefore, it is of great urgency to establish accurate atomic mobility databases for the liquid phase. Recently, Chen et al. [21] proposed a modified 
Sutherland equation to establish the correlation between diffusivity and viscosity. Such an equation allows the prediction of different diffusivities in target alloys and development of atomic mobility databases for melts. The reliability of predicting self- and impurity diffusivities in liquid metals by using this method has been verified by serval groups [22, 23, 27-29]. In the present work, for those liquid systems where the experimental data is not available, the modified Sutherland equation proposed by Chen et al. [21] is used for estimation.

Introduction to Diffusion Module and Precipitation Module. The Diffusion Module, known as DICTRA $[16,17]$ previously, is now an add-on module to Thermo-Calc. It is used to simulate the diffusion controlled transformations in multicomponent systems. During a DICTRA simulation, the multicomponent diffusion equations in various regions of a material are solved under the assumption that thermodynamic equilibrium holds locally at all phase interfaces. The simulations are one-dimensional with three simple geometries: planar, cylindrical and spherical.

The Precipitation Module, formerly referred to as TC-PRISMA [18, 19], is also an add-on module to the Thermo-Calc software package. This module deals with a specific and very important phase transformation process, i.e. precipitation of a large number of small and dispersed particles from a matrix phase in multicomponent systems. It is based on the Langer-Schwartz theory [30] and adopts the Kampmann Wagner numerical approach [31] to solve the governing equation for the evolution of particle size distribution function. With the Precipitation Module, the nucleation, growth, and coarsening of precipitate phases can be simulated simultaneously by tracking the evolution of the probability distribution of the particle number densities, and the results can be obtained about the mean radius, number density, and volume fraction as well as particle size distribution of a precipitate.

In order to perform a simulation in the Diffusion Module and Precipitation Module, both a thermodynamic database and an atomic mobility database are needed. In addition to bulk thermodynamic and kinetic data, a few other physical properties, such as interfacial energy and volume, are needed in precipitation models. These additional physical parameters can be obtained by experiments or other estimation models or first principles calculations.

\section{Model Description}

Diffusion Modeling. Let us start this section from the diffusion flux in one dimension (z-direction). The diffusion flux of element $i$ in an $n$-component substitutional phase within the lattice-fixed frame is expressed as [32]

$$
J_{i}^{L}=-c_{i} M_{i} \nabla \mu_{i}
$$

where $c_{i}$ is the molar concentration of element $i$, and $c_{i}=x_{i} / V_{m} . x_{i}$ and $V_{m}$ are the molar fraction and molar volume, respectively. $M_{i}$ is the atomic mobility of element $i$, and $\mu_{i}$ is the chemical potential. $L$ stands for the lattice-fixed frame. Converting the chemical potential gradient to the concentration gradient in Eq. (1), we have

$$
J_{i}^{L}=-c_{i} M_{i} \sum_{j=1}^{n-1}\left(\frac{\partial \mu_{i}}{\partial x_{j}}-\frac{\partial \mu_{i}}{\partial x_{n}}\right) \frac{\partial x_{j}}{\partial z} .
$$

Meanwhile, based on Fick's first law, the diffusion flux related to the diffusivity in the lattice fixed frame of reference is given by

$$
J_{i}^{L}=-\sum_{j}^{n-1}{ }^{I} D_{i j} \nabla c_{j}
$$


in which, ${ }^{I} D_{i j}$ is the intrinsic diffusivity with $n$ being the dependent element. Equating Eq. (2) and Eq. (3), the expression for intrinsic diffusivity of $i$ can then be obtained as follows:

$$
{ }^{I} D_{i j}^{n}=x_{i} M_{i}\left(\frac{\partial \mu_{i}}{\partial x_{j}}-\frac{\partial \mu_{i}}{\partial x_{n}}\right)=F_{i j}^{n} R T M_{i}
$$

with $F_{i j}^{n}=\frac{1}{R T} x_{i}\left(\frac{\partial \mu_{i}}{\partial x_{j}}-\frac{\partial \mu_{i}}{\partial x_{n}}\right)$, which is called the thermodynamic factor. It should be noted here, $F_{i j}^{n}$ is only related to the thermodynamic description of the system. In the present work, the thermodynamic factor can be directly calculated with use of the thermodynamic database (TCCU) [15]. $R$ is the gas constant $\left(\mathrm{J} \mathrm{mol}^{-1} \mathrm{~K}^{-1}\right)$, and $T$ is absolute temperature in $\mathrm{K}$.

Similar to Eq. (3), the diffusion flux of $i$ in the volume-fixed frame is

$$
J_{i}^{V}=-\sum_{j}^{n-1} \tilde{D}_{i j}^{n} \nabla c_{j}
$$

Here $\tilde{D}_{i j}^{n}$ is the inter-diffusion coefficient, which means the diffusivity of element $i$ in the gradient of component $j$ with element $n$ as the reference component. $V$ stands for the volume-fixed frame. The diffusion flux in the lattice-fixed frame and volume-fixed frame should satisfy the following relationship [33]

$$
J_{i}^{V}=J_{i}^{L}-x_{i} \sum_{j}^{n} J_{j}^{L}
$$

Then, the relationship between inter-diffusivity and intrinsic diffusivity can be evaluated as follows:

$$
\tilde{D}_{i j}^{n}={ }^{I} D_{i j}-x_{i} \sum_{k=1}^{n}{ }^{I} D_{k j} .
$$

Combining Eq. (4) and Eq. (7), we have the expression for the inter-diffusivity:

$$
\tilde{D}_{i j}^{n}=\sum_{k=1}^{n}\left(\delta_{k i}-x_{i}\right) x_{k} M_{k}\left(\frac{\partial \mu_{k}}{\partial x_{j}}-\frac{\partial \mu_{k}}{\partial x_{n}}\right) .
$$

Besides, based on the Einstein relation [34], the tracer diffusivity $\left(D_{i}^{*}\right)$ of element $i$ related to the mobility parameter is given as:

$$
D_{i}^{*}=R T M_{i} .
$$

It is clear from Eq. (9) that the tracer diffusivity is independent of the thermodynamic factor.

The atomic mobility $\left(M_{i}\right)$ can be described from the absolute-reaction theory. According to the suggestion by Andersson and Ågren [35] and Jönsson [36], $M_{i}$ is expressed as:

$$
M_{i}=\frac{1}{R T} M_{0} \exp \left(\frac{-Q_{i}}{R T}\right)^{m g} \Omega,
$$


where $M_{0}$ is the frequency factor and $Q_{i}$ is the activation energy, which are dependent on composition, temperature, and pressure. ${ }^{m g} \Omega$ is the ferromagnetic coefficient. For the liquid and Fcc_A1 copper alloys, the ferromagnetic contribution to the diffusion coefficient is negligible, therefore ${ }^{m g} \Omega$ is unit. Merge the frequency factor and activation energy into one parameter, and let $\Phi_{i}=-Q_{i}+R T \ln M_{0}$, Eq. (10) can be rewritten as:

$$
M_{i}=\exp \left(\frac{-\Phi_{i}}{R T}\right) \frac{1}{R T}
$$

Again following the suggestion of Andersson and Ågren [35], $\Phi_{i}$ can be represented by using the Redlich-Kister polynomial [37] in the spirit of the CALPHAD method:

$$
\Phi_{i}=\sum_{j} x_{j} \Phi_{i}^{j}+\sum_{p} \sum_{j>p} x_{j} x_{p}\left[\sum_{k=0} \Phi_{i}^{p, j}\left(x_{p}-x_{j}\right)^{k}\right]+\sum_{p} \sum_{j>p} \sum_{q>p} x_{j} x_{p} x_{q}\left[\sum_{s} v_{p j q}^{s}{ }^{s} \Phi_{i}^{p, j, q}\right] \quad(s=p, j, q),
$$

where $\Phi_{i}^{j}$ is the value of $\Phi_{i}$ for element $i$ in pure $j$, and $\Phi_{i}^{p, j}$ and $\Phi_{i}^{p, j, q}$ are the binary and ternary interaction parameters, respectively. The coefficients $\Phi_{i}^{j}, \Phi_{i}^{p, j}$ and $\Phi_{i}^{p, j, q}$ can be evaluated from the experimental diffusion coefficients, i.e. tracer diffusivity, intrinsic diffusivity and inter-diffusivity. The parameter $v_{p j q}^{s}$ is in the form:

$$
v_{p j q}^{s}=x_{s}+\left(1-x_{p}-x_{j}-x_{q}\right) / 3 \text {. }
$$

The chemical potential $\mu_{i}$ in Eqs. (1), (4) and (8) is given by

$$
\mu_{i}=G_{m}+\frac{\partial G_{m}}{\partial x_{i}}-\sum_{j=1}^{n} x_{j} \frac{\partial G_{m}}{\partial x_{j}}
$$

where $G_{m}$ is the molar Gibbs energy of the target phase, i.e. the liquid or Fcc_A1 phase in the present work, which is described as:

$$
\begin{array}{r}
G_{m}=\sum_{j=1}^{n} x_{j}{ }^{0} G_{j}+R T \sum_{j=1}^{n} x_{j} \ln \left(x_{j}\right)+\sum_{p} \sum_{j>p} x_{p} x_{j}\left[\sum_{k=0}{ }^{k} L_{p j}\left(x_{p}-x_{j}\right)^{k}\right]+\sum_{p} \sum_{j>p} \sum_{q>p} x_{p} x_{j} x_{q}\left[\sum_{s=0} v_{p j q}^{s}{ }^{s} L_{p j q}\right] \\
(s=p, j, q)
\end{array}
$$

in which, ${ }^{0} G_{j}$ is the reference Gibbs energy for each pure element. $L_{p j}$ and $L_{p j q}$ are the assessed binary and ternary interaction parameters, respectively. In the present work, the reliable molar Gibbs energy descriptions of the liquid and Fcc_A1 phases can be directly obtained from our recently developed copper-based thermodynamic database (TCCU).

Modified Sutherland Equations. One of the major obstacles to establish the atomic mobility database for liquid multicomponent alloys is the lack of adequate measurements of diffusion coefficients due to experimental difficulties caused by convections in melts. In the present work, MOBCU includes also the atomic mobility data for the liquid phase. As mentioned in Section Development Strategy, for those liquid systems without experimental diffusion data, the recently proposed modified Sutherland equation [21] is utilized to estimate the Arrhenius formula for the self-diffusivity and impurity diffusivity in pure metallic melts. The expressions for estimated Arrhenius formula of self- and impurity diffusivities are given below as [21]: 


$$
D_{i}^{i}={ }^{0} D_{i}^{i} \cdot \exp \left(\frac{-Q_{i}^{i}}{R T}\right), \quad D_{i}^{j}={ }^{0} D_{i}^{j} \cdot \exp \left(\frac{-Q_{i}^{j}}{R T}\right)
$$

with

$$
\begin{aligned}
& D_{i}^{i}=\frac{3.2178 \times 10^{-16} \cdot e^{\frac{\alpha_{i}}{3} T_{i}^{m}}\left(V_{i}^{m}\right)^{1 / 3} \sqrt{T_{i}^{m}}}{C_{1} W_{i}^{1 / 2}}, \\
& Q_{i}^{i}=\left(C_{2}+\frac{1}{2}+\frac{\alpha_{i}}{3} T_{i}^{m}\right) R T_{i}^{m}, \\
& { }^{0} D_{i}^{j}=\frac{2.1452 \times 10^{-16} \cdot e^{\left(2 \alpha_{j}-\frac{\alpha_{i}}{1+\alpha_{i}\left(T_{j}^{m}-T_{i}^{m}\right)}\right) T_{j}^{m} / 3}\left(V_{j}^{m}\right)^{2 / 3} \sqrt{T_{j}^{m}}}{C_{1} W_{j}^{1 / 2}\left[1+\alpha_{i}\left(T_{j}^{m}-T_{i}^{m}\right)\right]^{1 / 3}} \cdot\left(\frac{1+\frac{3 \eta_{j}}{\beta r_{j}}}{2 \eta_{j}}\right), \\
& Q_{i}^{j}=\left(C_{2}+\frac{1}{2}+\frac{2 \alpha_{j}}{3} T_{j}^{m}-\frac{1}{3} \cdot \frac{\alpha_{i} T_{j}^{m}}{1+\alpha_{i}\left(T_{j}^{m}-T_{i}^{m}\right)}\right) R T_{j}^{m},
\end{aligned}
$$

where $\eta_{i}, \alpha_{i}, r_{i}, W_{i}, V_{i}$ and $T_{i}^{m}$ are the dynamic viscosity, the radius of the diffusing unit, the thermal coefficient, the atomic mass, the absolute molar volume and the melting point of the pure element $i$, respectively. $\beta$ in Eq. (19) is the coefficient of sliding friction between the diffusing particle and medium. The value of $\beta$ is determined by the atomic radii and melting temperatures of the solute and solvent elements. When a large solute atom moves among smaller solvent atoms, the coefficient $\beta$ becomes infinite. In another extreme case where a small solute atom moves among solvent atoms of an equal or larger size, the small solute atoms can travel well enough between the gaps of the larger solvent atoms. In this case, $\beta$ is equal to 0 . Besides, when the melting temperature of solute $i\left(T_{i}^{m}\right)$ is lower than that of solvent $j\left(T_{j}^{m}\right)$, the coefficient $\beta$ can thus also be regarded as equal to $0 . C_{1}$ and $C_{2}$ are constants, which are suggested to be $(1.80 \pm 0.39) \times 10^{-8}\left(\mathrm{JKmol}^{-1 / 3}\right)^{1 / 2}$ and $(2.34 \pm 0.20)$ by Chen et al. [21], respectively.

\section{Verification and Validation of the Database}

In order to verify and validate the present mobility database, the comparison between calculated diffusivities/simulated diffusion behaviors and corresponding experimental data in various copper-based alloys is performed. In the following two sections, some representative results are presented.

Calculation of Diffusivities. All diffusivity data collected for the binary, ternary and quaternary systems given in Table 1 are used to verify the presently developed mobility database. In this section, various calculated diffusivities i.e. self-, tracer and chemical diffusivities in both the liquid and Fcc_A1 phases are compared with the reported experimental data.

Figure 2(a) presents the presently calculated self-diffusivities of $\mathrm{Al}, \mathrm{Cu}, \mathrm{Fe}, \mathrm{Mn}$, and $\mathrm{Zn}$ in the liquid state along with the experimental data [38-43] and theoretically predicted data [44-55]. In Fig. 2(b), the calculated tracer diffusivities of $\mathrm{Cu}$ (blue lines) in liquid $\mathrm{Al}-20 \mathrm{at} . \% \mathrm{Cu}$ and $\mathrm{Ag}-85.4 \mathrm{at} . \% \mathrm{Cu}$ alloys are compared with the reported experimental data [56-58]. Besides, the calculated tracer diffusivities of $\mathrm{Ni}$ (red lines) in liquid Al-20at.\%Ni and $\mathrm{Si}-20 \mathrm{at} . \% \mathrm{Ni}$ alloys along with measured data $[59,60]$ is also presented in Fig. 2(b). As shown in the figures, the calculated liquid diffusivities agree excellently with both measurements and theoretical predications. 


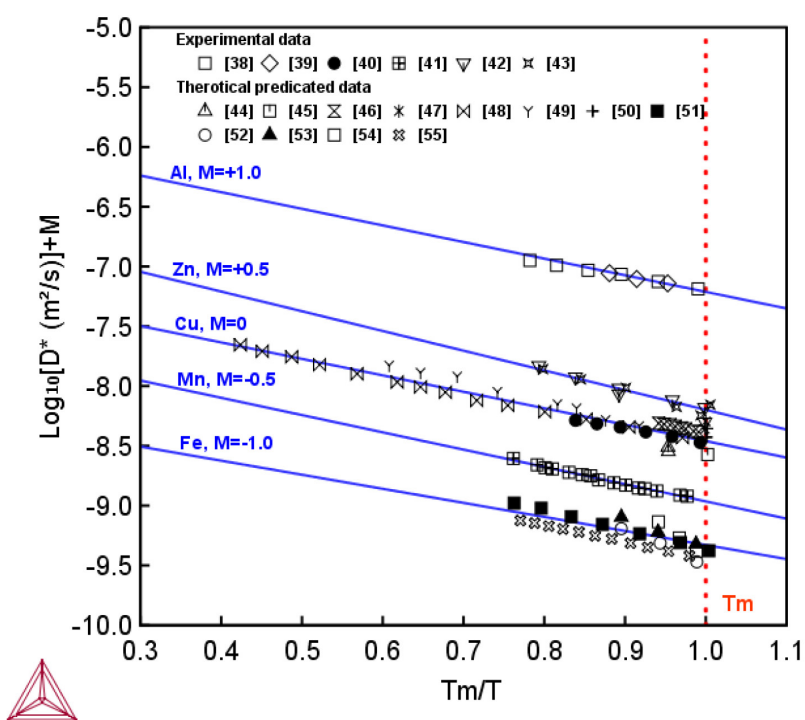

(a)

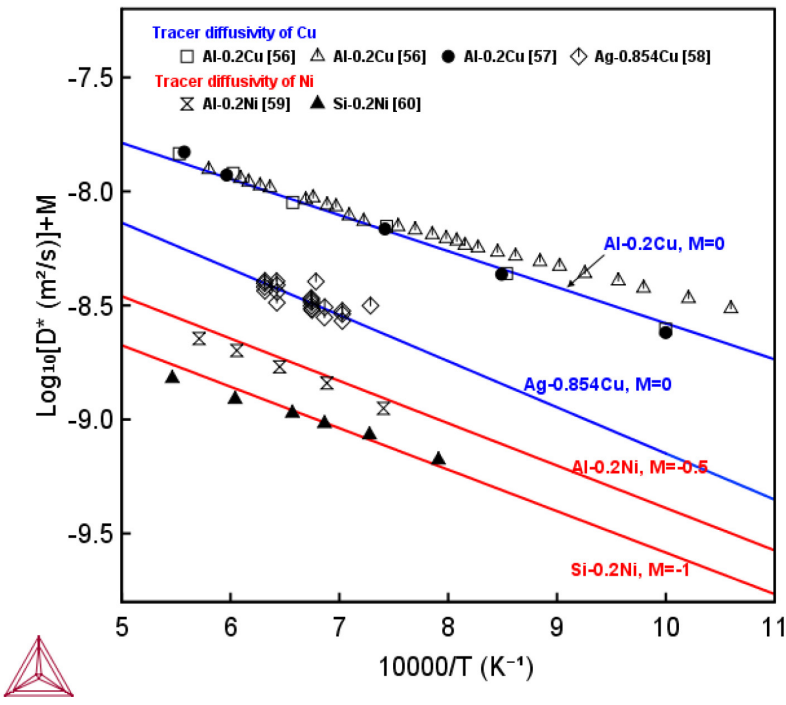

(b)

Figure 2 (a) Calculated self-diffusivities of $\mathrm{Al}, \mathrm{Cu}, \mathrm{Fe}, \mathrm{Mn}$ and $\mathrm{Zn}$ in the liquid state compared with experimental data [38-43] and theoretical predicted data [44-55]; (b) calculated tracer diffusivity of $\mathrm{Cu}$ in $\mathrm{Al}-\mathrm{Cu}, \mathrm{Ag}-\mathrm{Cu}$ melts, and tracer diffusivity of $\mathrm{Ni}$ in Al-Ni and Ni-Si melts along with experimental data [56-60]. A constant, $\mathrm{M}$, has been added to separate the data.

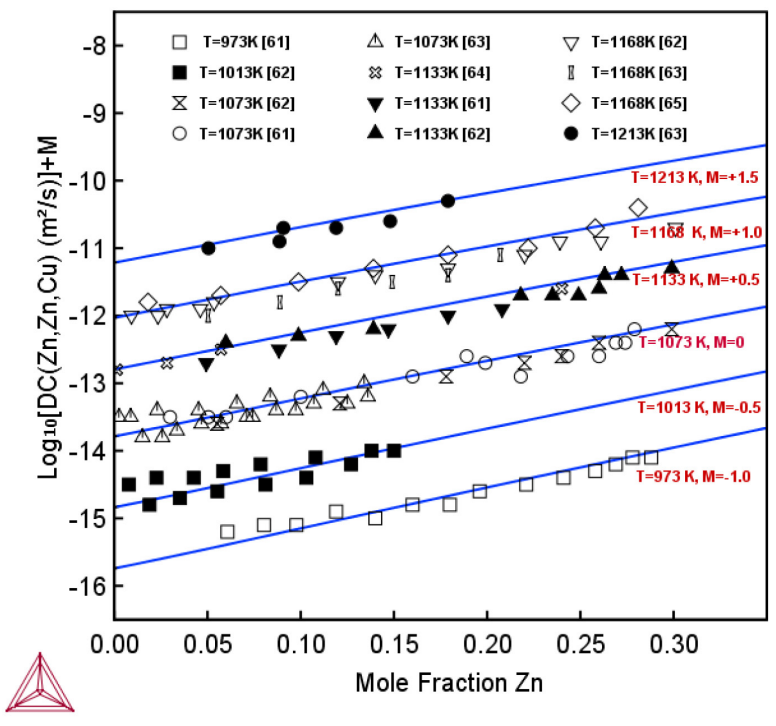

(a)

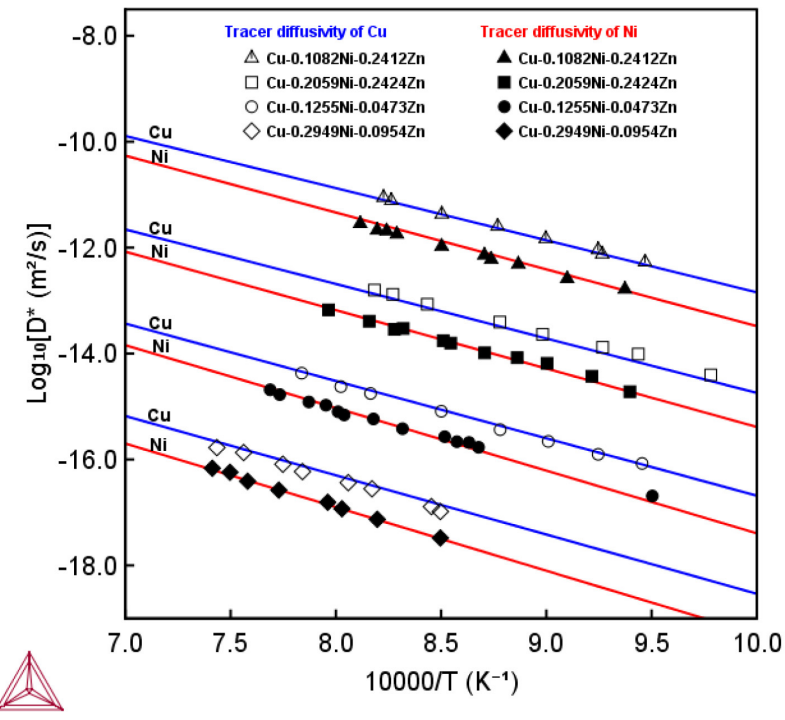

(b)

Figure 3 (a) Comparison between the calculated interdiffusion coefficients in fcc $\mathrm{Cu}$ - $\mathrm{Zn}$ alloys from 973 to $1213 \mathrm{~K}$ and experimental data [61-65]; (b) calculated tracer diffusivities of $\mathrm{Cu}$ and $\mathrm{Ni}$ in several fcc $\mathrm{Cu}-\mathrm{Ni}$-Zn ternary alloys along with experimental data [66-68]. A constant, $\mathrm{M}$, has been added to separate the data.

Figure 3(a) shows the comparison between the calculated interdiffusion coefficients in fcc $\mathrm{Cu}-\mathrm{Zn}$ alloys from 973 to $1213 \mathrm{~K}$ and the measurements available in the literature [61-65]. A good agreement between the calculations and the experiments is obtained. Figure 3(b) presents the calculated temperature dependence of the tracer diffusivities of $\mathrm{Cu}$ (blue lines) and $\mathrm{Ni}$ (red lines) in several fcc $\mathrm{Cu}-\mathrm{Ni}-\mathrm{Zn}$ ternary alloys, which can reproduce well the experimental data [66-68]. Moreover, the values of tracer diffusivity of $\mathrm{Cu}$ are larger than that of $\mathrm{Ni}$ in $\mathrm{Cu}-\mathrm{Ni}-\mathrm{Zn}$ system as can be easily seen in Fig. 3(b). The good agreement between present calculation and experimental diffusivity data for both the liquid and Fcc_A1 phases indicates the reliability of MOBCU.

Figure 4 shows presently predicted contour map of main interdiffusion coefficients $\left(\tilde{D}_{A I A l}^{C u}\right.$ and $\tilde{D}_{M n M n}^{C u}$ ) in the fcc Cu-Al-Mn system at $800{ }^{\circ} \mathrm{C}$. As presented in Fig. 4, $\tilde{D}_{A l A l}^{C u}$ and $\tilde{D}_{M n M n}^{C u}$ show quite 
different composition dependent behaviors in the copper corner of the $\mathrm{Cu}-\mathrm{Al}-\mathrm{Mn}$ ternary system. Both $\tilde{D}_{A l A l}^{C u}$ and $\tilde{D}_{M n M n}^{C u}$ increase as the increase of the concentration of $\mathrm{Al}$ and $\mathrm{Mn}$, but the diffusivity of $\mathrm{Al}$ is more sensitive with concentration comparing with that of $\mathrm{Mn}$. Besides, the diffusion of $\mathrm{Al}$ shows stronger concentration dependence on the $\mathrm{Cu}-\mathrm{Al}$ side than the $\mathrm{Cu}-\mathrm{Mn}$ side, as shown in Fig. 4(a), while the diffusivity of $\mathrm{Mn}$ is more sensitive to concentration on the $\mathrm{Cu}-\mathrm{Mn}$ side. The presently predicted diffusion behaviors in $\mathrm{Cu}-\mathrm{Al}-\mathrm{Mn}$ alloys have been verified by the reported experimental information [69].

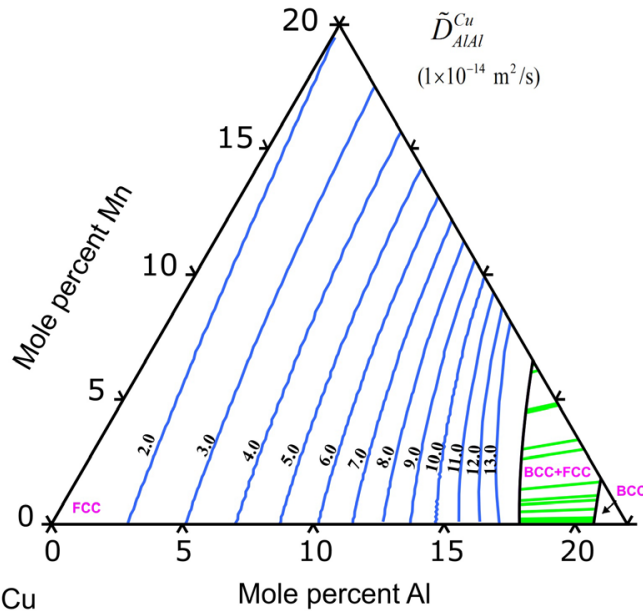

(a)

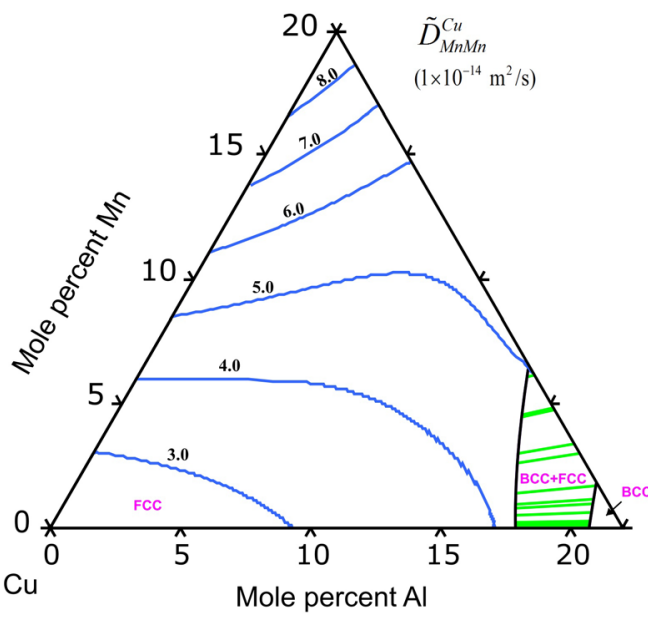

(b)

Figure 4 The predicted contour map for the main interdiffusion coeffcients (a) $\tilde{D}_{A l A l}^{C u}$, and (b) $\tilde{D}_{M n M n}^{C u}$ in fcc Cu-Al-Mn alloys at $800{ }^{\circ} \mathrm{C}$.

Simulation of Diffusion Couples. The reliability of present mobility database is then validated by comparing the predicted concentration profiles and diffusion paths in several ternary and quaternary diffusion couples with the reported experimental data. The simulation is performed by using the Diffusion Module together with the mobility database (MOBCU) and thermodynamic database (TCCU).

The $\mathrm{Cu}-\mathrm{Sn}-\mathrm{Zn}$ based alloys are one of the most important commercial copper alloys with high strength and corrosion resistances [70, 71]. To have a better understanding of the $\mathrm{Cu}-\mathrm{Sn}-\mathrm{Zn}$ system, an accurate description of its diffusion behavior is needed. Hereunder we shall show the above verified mobility database is capable to predict the concentration profiles and diffusion paths in $\mathrm{Cu}-\mathrm{Sn}-\mathrm{Zn}$ diffusion couples. Figures 5(a) and 5(b) show the simulated concentration profiles of $\mathrm{Cu}-4.7$ at.\%Zn/Cu-6.9at.\%Sn and $\mathrm{Cu} / \mathrm{Cu}-2.4$ at.\%Zn-6.2at.\%Sn diffusion couples annealed at $800{ }^{\circ} \mathrm{C}$ for $78300 \mathrm{~s}$, compared with experimental measurements from Takahashi et al. [72]. The calculated diffusion paths for the corresponding diffusion couples under the same simulated conditions are presented in Fig. 5(c), which coincide extremely well with the corresponding experimental data points [72]. In general, if one draws a straight line that links the terminal compositions of a single-phase ternary diffusion couple, the diffusion path for the diffusion couple should intersect with the straight line at least one time [73]. Due to the different diffusion coefficients and the constraint on the mass balance of the three diffusion species in the diffusion zone, both diffusion paths are $\mathrm{S}$-shaped. The excellent agreements indicate the presently developed mobility database has a reliable diffusion description for the $\mathrm{Cu}-\mathrm{Sn}-\mathrm{Zn}$ ternary system. 


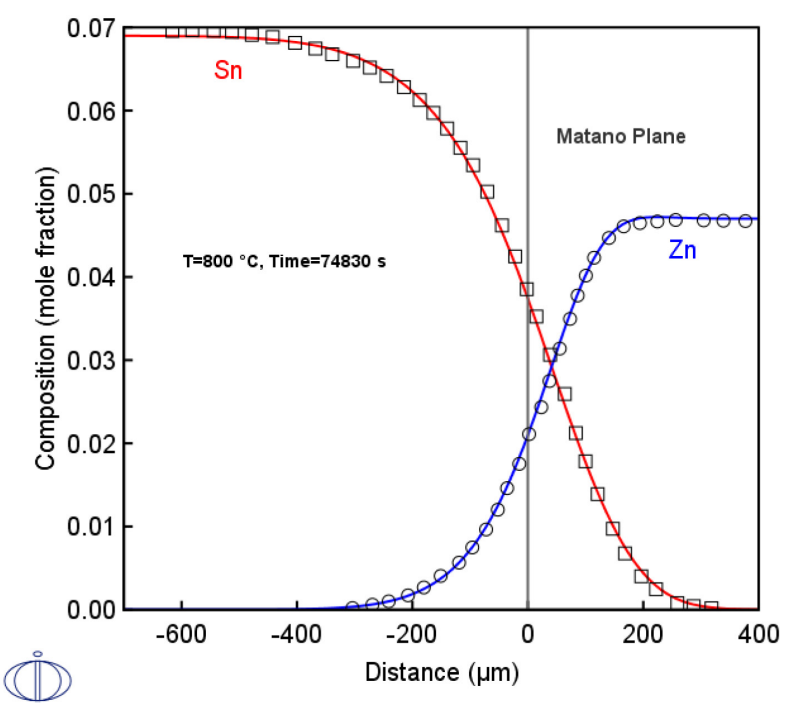

(a)

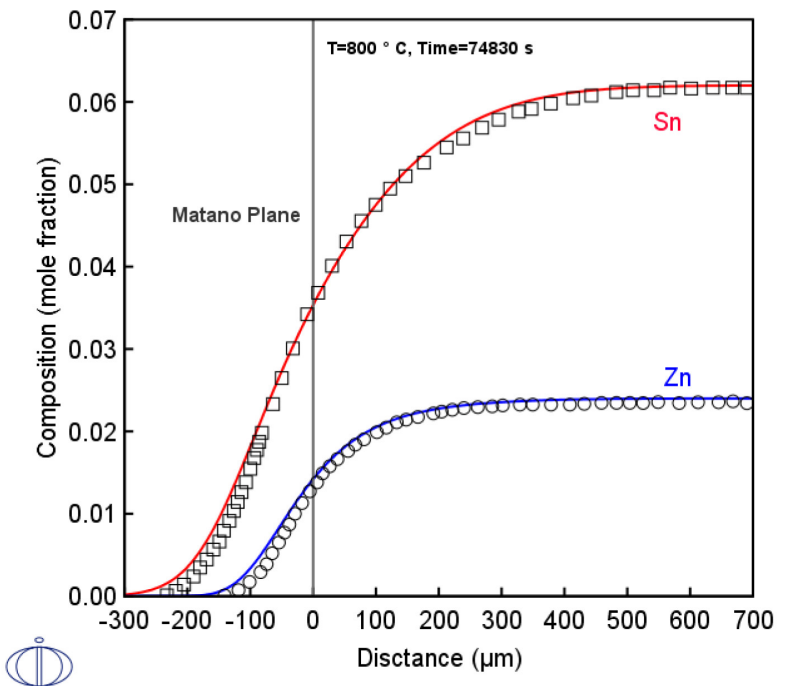

(b)

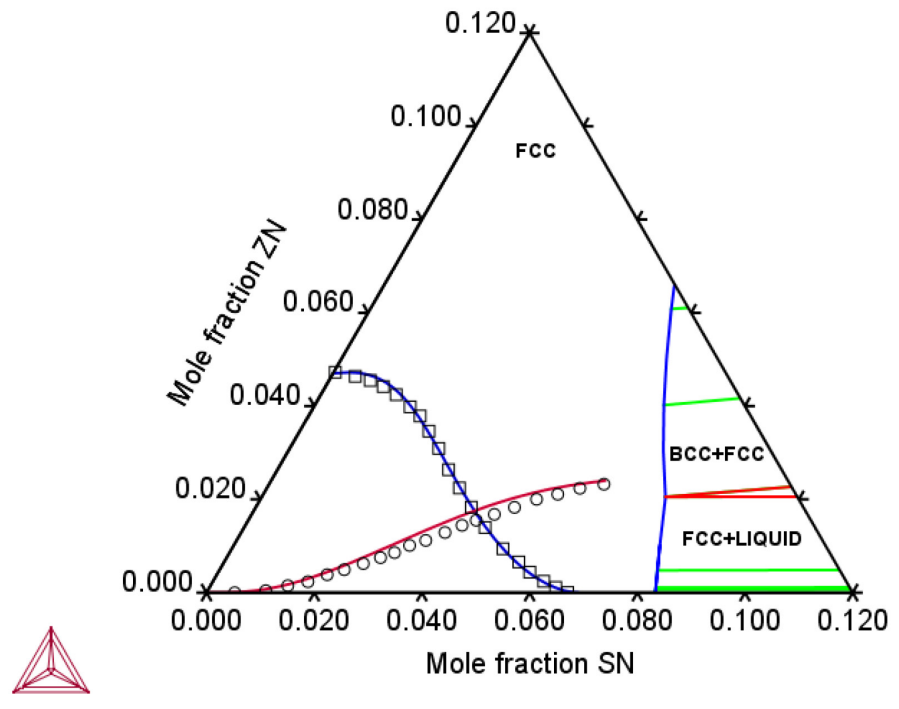

(c)

Figure 5 Simulated concentration profiles for $\mathrm{Cu}-\mathrm{Sn}-\mathrm{Zn}$ ternary diffusion couples (a)Cu-4.7 at.\%Zn/Cu-6.9at.\%Sn, (b) $\mathrm{Cu} / \mathrm{Cu}-2.4$ at.\%Zn-6.2at.\%Sn, and (c) corresponding diffusion paths along with experimental measurements (symbols) [72]. The diffusion couples annealed at $800{ }^{\circ} \mathrm{C}$ for $74830 \mathrm{~s}$.

With the atomic mobility parameters in binary and ternary systems, the diffusion properties in quaternary systems can also be resonably predicted based on direct extrapolations. Figure 6 presents the concentration profiles and diffusion fluxs of two fcc $\mathrm{Cu}-\mathrm{Ni}-\mathrm{Mn}-\mathrm{Zn}$ quateranry diffusion couples, which were anealed at $775{ }^{\circ} \mathrm{C}$ for $172800 \mathrm{~s}$. Figs. 6(a) and 6(c) depict the simulated concentration profiles and diffusion fluxes for the $\mathrm{Cu}-21.3$ at.\%Ni-17.6at.\% $\mathrm{Zn} / \mathrm{Cu}-20.3 \mathrm{at} . \% \mathrm{Ni}-9.2 \mathrm{at} . \% \mathrm{Mn}$ diffusion couple, respectivley. The simulated concentration profiles for $\mathrm{Cu}, \mathrm{Mn}, \mathrm{Ni}$ and $\mathrm{Zn}$ lie very close to the expremental data [74]. It can be found in Figs. 6(a) and 6(c) that the slopes of the cocnention profiles for the $\mathrm{Cu}-21.3 \mathrm{at} . \% \mathrm{Ni}-17.6 \mathrm{at} . \% \mathrm{Zn} / \mathrm{Cu}-20.3 \mathrm{at} . \% \mathrm{Ni}-9.2 \mathrm{at} . \% \mathrm{Mn}$ diffusion couple have same signs on both right and left sides of the Matano plane, while the slopes of diffusion fluxes are of opppoite signs. Such behavior indicates that this diffussion couple has a normal homogenization diffusion process. The concentration profiles and diffusion fluxes for the Cu-18.6at.\%Zn -10.4at.\%Mn/Cu-21.3at.\%Ni-17.6at.\%Zn diffusion couple are shown in Figs. 6(b) and 6(d). As shown in Fig. 6(b), there are humps on the concentration profiles of $\mathrm{Cu}$ and $\mathrm{Mn}$, which can be explained by the uphill diffusion phenomena. Such phenomena can be further verified by the simualted diffusion fluxes. As shown in Fig. 6(d), the slope of the diffusion flux for $\mathrm{Cu}$ changes from negative to positive on both left and right sides of the Matano plane, which indicates that the flow of 
the $\mathrm{Cu}$ atoms migrates against its concentration gradient. Similar explainations can be made for Mn. The general good agreement between the calculations and measurements demonstrates the predictive power of the CALPHAD method embodied in the present atomic mobility database and suggests a high confidence level in making direct extrapolations into higher-order systems on the basis of the information in binary and ternary systemts.

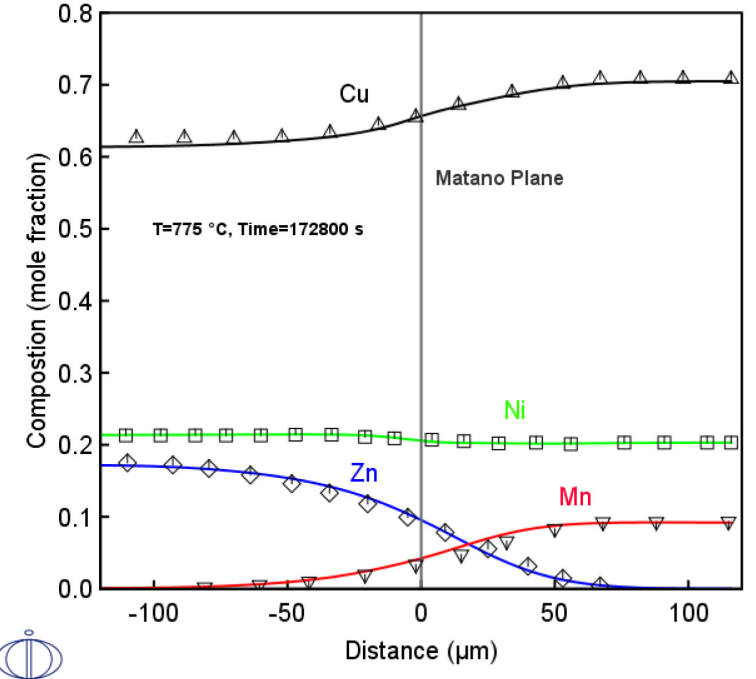

(a)

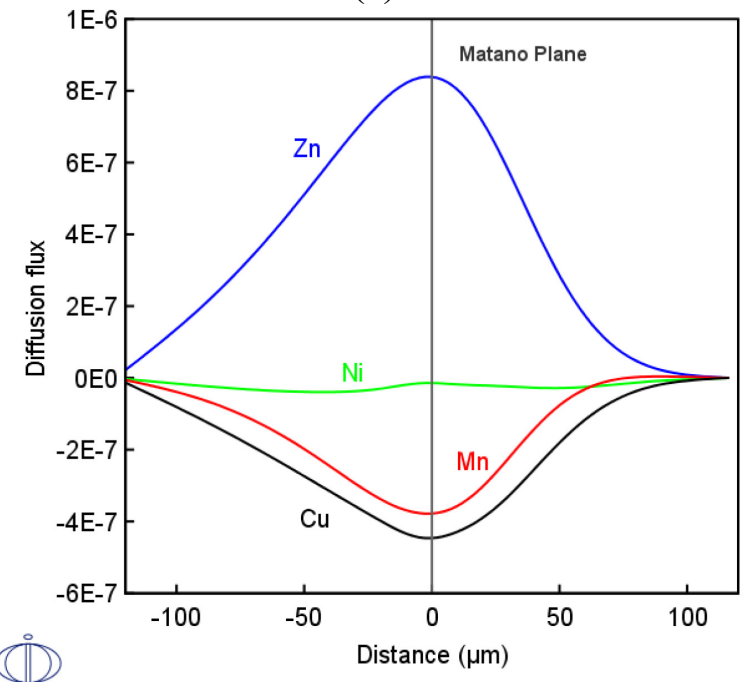

(c)

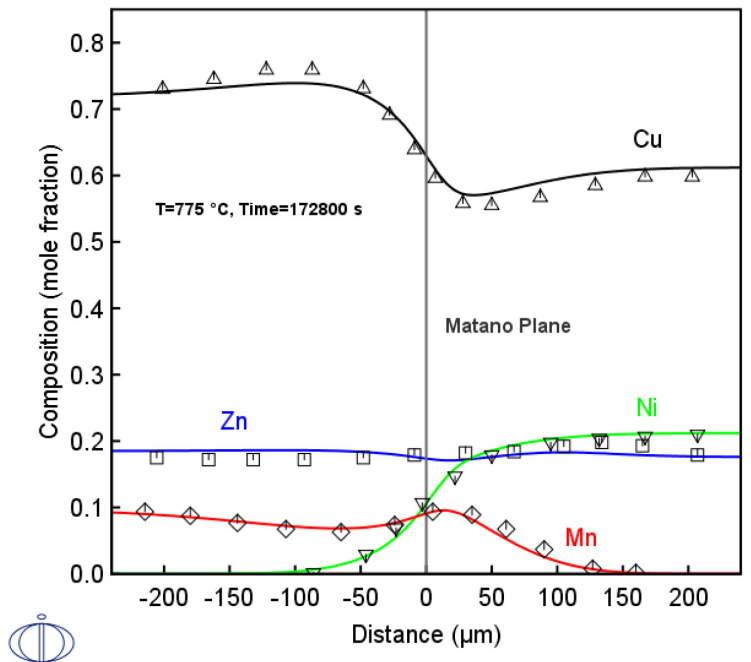

(b)

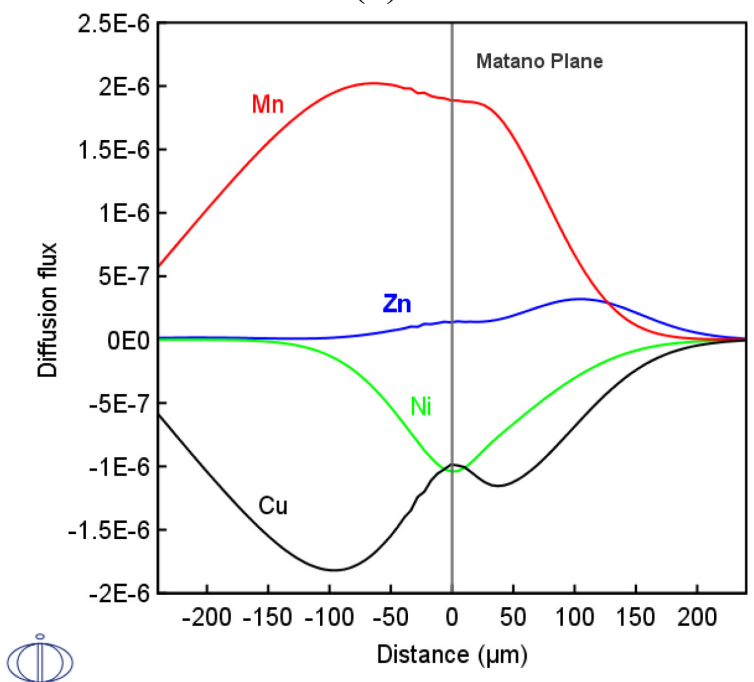

(d)

Figure 6 Simulated and measured concentration profiles of $\mathrm{Cu}, \mathrm{Mn}, \mathrm{Ni}$ and $\mathrm{Zn}$ for (a) $\mathrm{Cu}-21.3$ at.\%Ni-17.6at.\%Zn/Cu-20.3at.\%Ni-9.2at.\%Mn and (b) $\mathrm{Cu}-18.6 a t . \% \mathrm{Zn}-10.4 \mathrm{at} . \%$ $\mathrm{Mn} / \mathrm{Cu}-21.3$ at.\%Ni-17.6at.\%Zn diffusion couples annealed at $775{ }^{\circ} \mathrm{C}$ for $172800 \mathrm{~s}$. The corresponding diffusion fluxes are shown in (c) and (d) respectively.

\section{Kinetic Simulation of Phase Transformations - Database Applications}

Simulation of Solidification Process. Solidification is one of the most critical processes in copper alloys, which will determine the formation of the bulk microstructure and then directly affect the mechanical and chemical properties of the alloys [75]. Therefore, being able to accurately simulate the solidification behavior of a copper alloy is of great importance. Based on the presently obtained atomic mobility database together with the above mentioned thermodynamic database, the solidification process in copper alloys can be modeled by using the Diffusion Module of Thermo-Calc. During the simulation, the diffusion data in both the liquid and solid (Fcc_A1) phases are considered. In this section, the simulations for solidification in $\mathrm{Cu}-\mathrm{Pb}-\mathrm{Sn}$ and $\mathrm{Cu}-\mathrm{Pb}-\mathrm{Sn}$ - $\mathrm{Zn}$ alloys are presented. 
The solidification behaviors of $\mathrm{Cu}-4.7 \mathrm{wt} . \% \mathrm{~Pb}-5.2 \mathrm{wt} . \% \mathrm{Sn}$ and $\mathrm{Cu}-4.9$ wt.\%Pb-5.2wt.\%Sn-4.5wt.\%Zn (nominal composition of Copper alloy C83600) alloys have been measured by Korojy et al. [76]. The solidification processes of these two alloys are simulated to make a comparison with the measurements. For the simulation, the initial liquid composition is assumed to be homogeneous and equal to the nominal alloy composition; the starting temperature for the solidification process is selected to be $20{ }^{\circ} \mathrm{C}$ higher than the equilibrium melting temperatures, i.e. $1030{ }^{\circ} \mathrm{C}$ for $\mathrm{Cu}-4.7 \mathrm{wt} . \% \mathrm{~Pb}-5.2 \mathrm{wt} . \% \mathrm{Sn}$ and $1010{ }^{\circ} \mathrm{C}$ for $\mathrm{Cu}-4.9 \mathrm{wt} . \% \mathrm{~Pb}-5.2 \mathrm{wt} . \% \mathrm{Sn}-4.5 \mathrm{wt} . \% \mathrm{Zn}$, which have been predicted by thermodynamic equilibrium calculations with use of TCCU; and the ending temperature is from the experimental information [76], i.e. $880{ }^{\circ} \mathrm{C}$ for alloy $\mathrm{Cu}-4.7 \mathrm{wt} . \% \mathrm{~Pb}-5.2 \mathrm{wt} . \% \mathrm{Sn}$ and $888{ }^{\circ} \mathrm{C}$ for $\mathrm{Cu}-4.9 \mathrm{wt} . \% \mathrm{~Pb}-5.2 \mathrm{wt} . \% \mathrm{Sn}-4.5 \mathrm{wt} . \% \mathrm{Zn}$, respectively. The simulation times are then calculated by time $=\frac{\left(T_{m}+20\right)-T_{\text {end }}}{v_{c}}$, where $T_{m}$ is the melting temperature, and $v_{c}$ is the cooling rate. The cooling rate is set to $0.16^{\circ} \mathrm{C} / \mathrm{s}$, which was reported by Korojy et al. [76]. The one-dimensional simulated domains are $285 \mu \mathrm{m}$ and $350 \mu \mathrm{m}$ for the $\mathrm{Cu}-5.2 \mathrm{wt} . \% \mathrm{Sn}-4.7 \mathrm{wt} . \% \mathrm{~Pb}$ and $\mathrm{Cu}-5.2 \mathrm{wt} . \% \mathrm{Sn}-4.5 \mathrm{wt} . \% \mathrm{Zn}-4.9 \mathrm{wt} . \% \mathrm{~Pb}$ alloys, which are estimated by measuring experimental half-width of the dendrite cross section and volume fraction of primary phase of the investigated alloys.

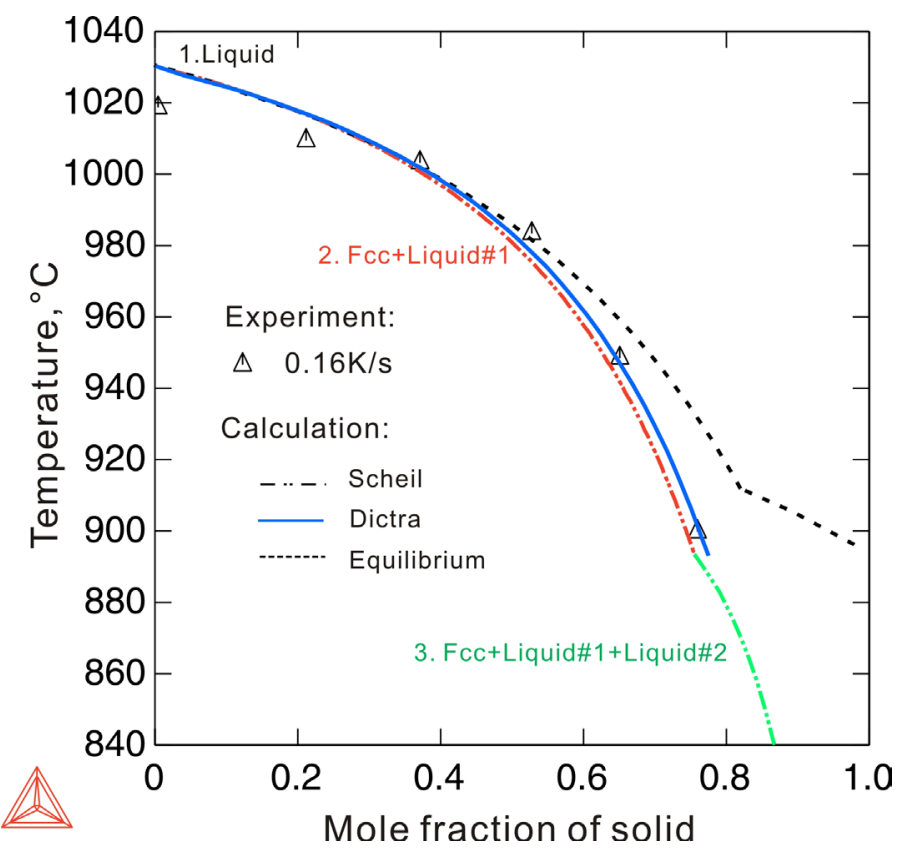

Figure 7 Simulated fraction of solid phase during the solidification process in $\mathrm{Cu}-4.7 \mathrm{wt} . \% \mathrm{~Pb}-5.2 \mathrm{wt} . \% \mathrm{Sn}$ alloy, compared with experimental data [76]. The cooling rate is $0.16{ }^{\circ} \mathrm{C} / \mathrm{s}$.

Figure 7 presents the DICTRA simulated increase of solid fraction (solid blue line) upon cooling of the $\mathrm{Cu}-4.7 \mathrm{wt} . \% \mathrm{~Pb}-5.2 \mathrm{wt} . \% \mathrm{Sn}$ alloy along with the experimental data [76]. The simulation results show an excellent agreement with the measurements. Besides, the equilibrium solidification results (black dashed line) and Scheil solidification results (dotted line) are also given in Fig. 7. Both of these results only depend on the phase equilibria in the system considered. It is not surprising that the equilibrium solidification results deviate from the experimental data because equilibrium solidification can only be attained with an extremely slow cooling rate. On the other hand, it could be easily seen that the Scheil solidification results are quite close the measurements, and show only slight underestimation. The Scheil solidification model assumes that the local equilibrium exists at the liquid/solid interface and the diffusion is absent in the solid phase but with perfect mixing in the liquid phase. With the cooling rate used in the experiments [76], it seems that the Scheil assumptions are fairly good for the $\mathrm{Cu}-4.7 \mathrm{wt} . \% \mathrm{~Pb}-5.2 \mathrm{wt} . \% \mathrm{Sn}$ alloy. It should be noted this does not mean that the Scheil model will always be sufficient for copper alloys. As a matter of fact, the cooling rate is not a 
part of the Scheil equation. Therefore, the effect of cooling rate and possible substantial back diffusions of some elements during slow cooling cannot be considered in a simple Scheil calculation. In order to provide an accurate prediction of the solidification behavior, the DICTRA simulation is recommended.

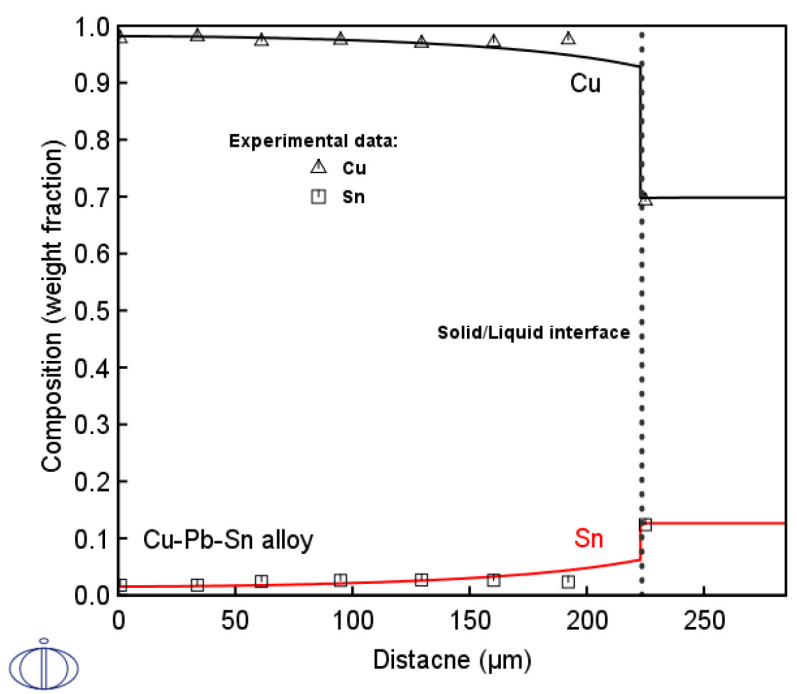

(a)

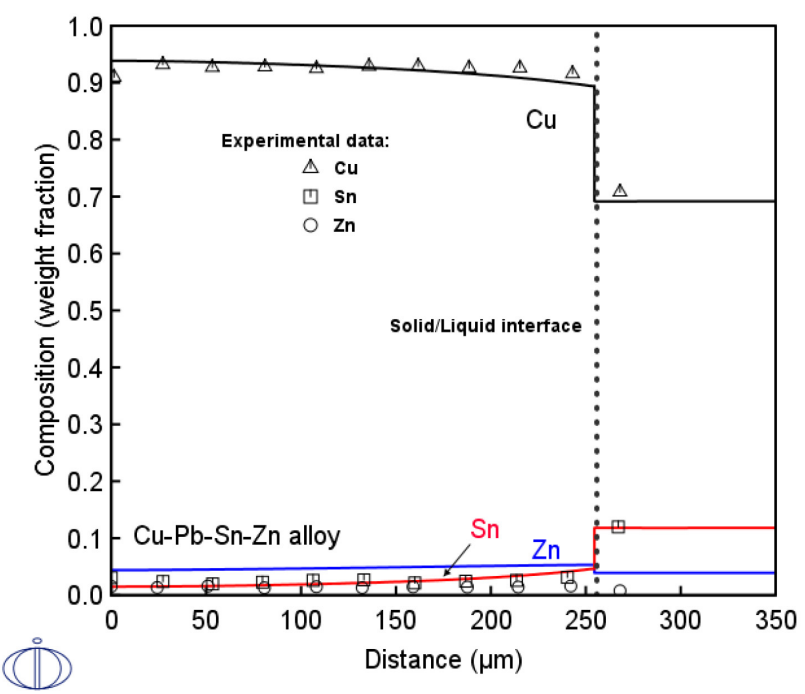

(b)

Figure 8 Calculated composition profile through half dendrite cross section in (a) $\mathrm{Cu}-4.7 \mathrm{wt} . \% \mathrm{~Pb}-$ 5.2wt.\%Sn alloy, and (b) $\mathrm{Cu}-4.9 \mathrm{wt} . \% \mathrm{~Pb}-5.2 \mathrm{wt} . \% \mathrm{Sn}-4.5 \mathrm{wt} . \% \mathrm{Zn}$ alloy during the solidification process along with experiemtnal data [76]. The cooling rate is $0.16{ }^{\circ} \mathrm{C} / \mathrm{s}$.

Figure 8 compares the simulated concentration profiles through half-width of the dendrite cross sections in the $\mathrm{Cu}-4.7 \mathrm{wt} . \% \mathrm{~Pb}-5.2 \mathrm{wt} . \% \mathrm{Sn}$ and $\mathrm{Cu}-4.9 \mathrm{wt} . \% \mathrm{~Pb}-5.2 \mathrm{wt} . \% \mathrm{Sn}-4.5 \mathrm{wt} . \% \mathrm{Zn}$ alloys with experimental data [76]. As can be seen, the presently simulated concentration profiles for $\mathrm{Sn}$ and $\mathrm{Cu}$ agree reasonably well with the experimental information except that for $\mathrm{Zn}$. Our simulated concentration of $\mathrm{Zn}$ in the solid phase is higher than the experimental one, as shown in Fig. 8(b). It is noticed that the experimental weight fraction of $\mathrm{Zn}$ in both liquid $(2.30 \mathrm{wt} . \%)$ and solid (4.35 wt.\%) phases after solidification process are less than the nominal composition (4.5 wt.\%), which indicates that the total mass of $\mathrm{Zn}$ in the treated alloy is less than that in the nominal alloy. Due to the obvious mass loss of $\mathrm{Zn}$ during the experiment, the simulated result for $\mathrm{Zn}$ is acceptable. As shown in Figs. $8(\mathrm{a})$ and (b), the concentration of solute $\mathrm{Sn}$ and $\mathrm{Zn}$ increases from the central to the edge of the dendrite in both $\mathrm{Cu}-4.7 \mathrm{wt} . \% \mathrm{~Pb}-5.2 \mathrm{wt} . \% \mathrm{Sn}$ and $\mathrm{Cu}-4.9 \mathrm{wt} . \% \mathrm{~Pb}-5.2 \mathrm{wt} . \% \mathrm{Sn}-4.5 \mathrm{wt} . \% \mathrm{Zn}$ alloys, while that of $\mathrm{Cu}$ shows a decrease trend. Moreover, the simulated content of $\mathrm{Sn}$ in the liquid phase is larger than that of in the solid phase in both the $\mathrm{Cu}-\mathrm{Pb}-\mathrm{Sn}$ and $\mathrm{Cu}-\mathrm{Pb}-\mathrm{Sn}-\mathrm{Zn}$ alloys, while the content of $\mathrm{Zn}$ shows an opposite trend. These simulated results have been confirmed by the experiments [76]. Besides, the length of the region on the left side of solid/liquid interface in Fig. 8 can be served as the simulated half-width of the dendrite after the solidification process. It shows that the simulated half-widths of dendrite in $\mathrm{Cu}-4.7 \mathrm{wt} . \% \mathrm{~Pb}-5.2 \mathrm{wt} . \% \mathrm{Sn}$ and $\mathrm{Cu}-4.9 \mathrm{wt} . \% \mathrm{~Pb}-5.2 \mathrm{wt} . \% \mathrm{Sn}-4.5 \mathrm{wt} . \% \mathrm{Zn}$ are $223 \mu \mathrm{m}$ and $256 \mu \mathrm{m}$ respectively, which agree reasonably with the experimental measured ones (225 $\mu \mathrm{m}$ and $268 \mu \mathrm{m})$.

Microsegregation occurs from solute partitioning during solidification processes. Such phenomenon will cause the formation of defects during the casting process and also has negative effects on the product quality due to the inhomogeneous microstructure and undesirable primary precipitates. The microsegregation behaviors of $\mathrm{Cu}-4.7 \mathrm{wt} . \% \mathrm{~Pb}-5.2 \mathrm{wt} . \% \mathrm{Sn}$ and $\mathrm{Cu}-4.9$ wt.\%Pb-5.2wt.\%Sn-4.5wt.\%Zn during the solidification can be predicted in the same DICTRA solidification simulation. The degree of microsegregation of the solutes can be quantified by the segregation coefficient, which is defined as follows [77, 78]: 


$$
k_{i}=\frac{c_{i}^{s}}{c_{i}^{l}},
$$

where $c_{i}^{s}$ and $c_{i}^{l}$ are the concentrations of elment $i$ in the solid and liquid near the interface, respectively. A value of $k_{i}$ less than unity indicates that the element $i$ prefers to remain in the liquid, and the concentration of $i$ thus increases in the liquid during solidification, whereas a value greater than unity indicates that the element is partitioning to the dendrite. The segregation coefficient highly depends on the system and solidification conditions, such as the composition and cooling rate. The predicted segregation coeffcients for $\mathrm{Sn}$ and $\mathrm{Zn}$ in the $\mathrm{Cu}-4.7 \mathrm{wt} . \% \mathrm{~Pb}-5.2 \mathrm{wt} . \% \mathrm{Sn}$ and $\mathrm{Cu}-4.9 \mathrm{wt} . \%$ $\mathrm{Pb}-5.2 \mathrm{wt} . \% \mathrm{Sn}-4.5 \mathrm{wt} . \% \mathrm{Zn}$ alloys during the solidification process are presented in Fig. 9. The segregation coefficient of $\mathrm{Sn}$ in both the $\mathrm{Cu}-\mathrm{Pb}-\mathrm{Sn}$ and $\mathrm{Cu}-\mathrm{Pb}-\mathrm{Sn}-\mathrm{Zn}$ alloys is less than 1 , and the segreation coefficient increases as the increase of solid fraction. While, the segregation coefficient for $\mathrm{Zn}$ in $\mathrm{Cu}-4.9 \mathrm{wt} . \% \mathrm{~Pb}-5.2 \mathrm{wt} . \% \mathrm{Sn}-4.5 \mathrm{wt} . \% \mathrm{Zn}$ alloy increase from 0.94 at the start of solidification to 1.41 at the end of the solidification, as shown in Fig. 9, which indicates that $\mathrm{Zn}$ has the inverse segregation during the solidification process. Besides, the segregation coefficient of $\mathrm{Sn}$ in $\mathrm{Cu}-4.7 \mathrm{wt} . \% \mathrm{~Pb}-5.2 \mathrm{wt} . \% \mathrm{Sn}$ alloy is larger than that in $\mathrm{Cu}-4.9 \mathrm{wt} . \% \mathrm{~Pb}-5.2 \mathrm{wt} . \% \mathrm{Sn}-4.5 \mathrm{wt} . \% \mathrm{Zn}$ alloy at the same solid fraction. It means that the addition of $\mathrm{Zn}$ will incerease the partitioning of $\mathrm{Sn}$ to the dendrite during the solidification. The predicted microsegregation behaviors in the $\mathrm{Cu}-\mathrm{Pb}-\mathrm{Sn}$ and $\mathrm{Cu}-\mathrm{Pb}-\mathrm{Sn}-\mathrm{Zn}$ alloys have been verified by the reported experimental measurements [76].

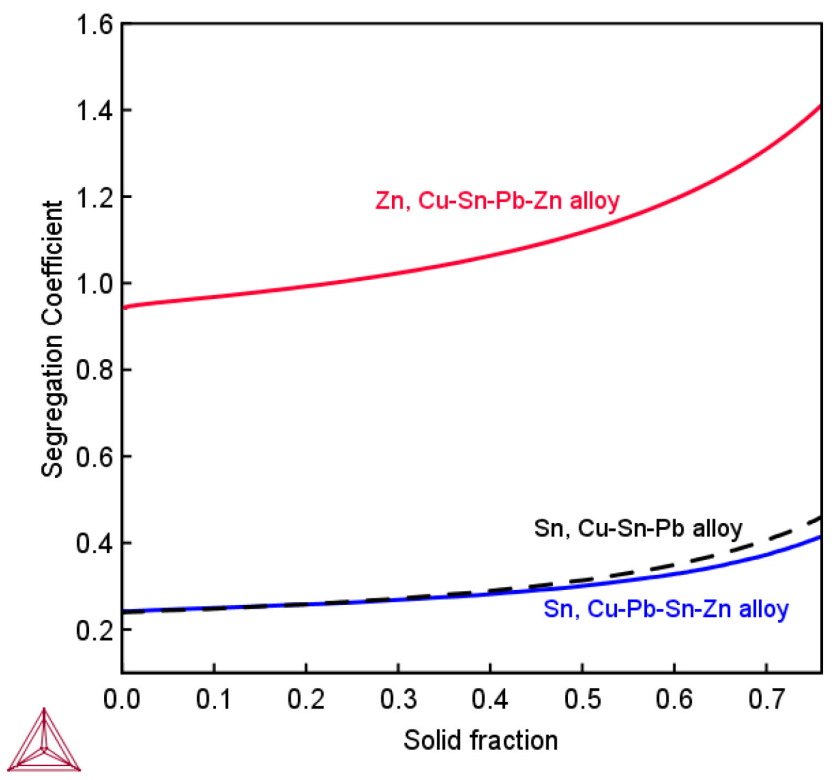

Figure 9 Predicted segregation coeffcients of $\mathrm{Sn}$ and $\mathrm{Zn}$ in $\mathrm{Cu}-4.7 \mathrm{wt} . \% \mathrm{~Pb}-5.2 \mathrm{wt} . \% \mathrm{Sn}$ and $\mathrm{Cu}-4.9 \mathrm{wt} . \% \mathrm{~Pb}-5.2 \mathrm{wt} . \% \mathrm{Sn}-4.5 \mathrm{wt} . \% \mathrm{Zn}$ alloys with solid fraction during the solidification process. The cooling rate is $0.16^{\circ} \mathrm{C} / \mathrm{s}$.

Simulation of Precipitation. Precipitation particle size and its distribution have a decisive influence on the subsequent mechanical properties of high-strength and highly conductive precipitation hardened copper alloys. The shape of precipitate particles, which is determined by the competition between the interfacial energy and elastic strain energy, has long been recognized as one of the potentially important factors in determining the strength of alloys. New settings are available in the Precipitation Module to treat non-spherical morphologies, including cuboid, plate, and needle, in the latest release (Version 2017b) [79]. In this section, the precipitations in several copper alloys with different precipitate morphologies are simulated by using the Precipitation Module (Version 2017b).

In order to use the Precipitation Module, both a thermodynamic and a kinetic database are needed. This is same as to use the Diffusion Module, but not enough. For precipitation simulation, additional physical properties are required as input data, for example, interfacial energy, volume, elastic constants or moduli. It should be noted that the Precipitation Module has an estimation model 
available for predicting interfacial energy. In the present simulations, experimental interfacial energy values will be used directly when suitable; otherwise the model estimated one will be accepted. The molar volume data for both the matrix and precipitate are directly calculated from the thermodynamic database (TCCU), which contains the volume parameters for each phase.

The first selected example is the precipitation of fcc $\mathrm{Co}-\mathrm{Fe}$ in the $\mathrm{Cu}-0.68$ at.\%Co- 1.52 at.\%Fe alloy, which has been experimentally investigated by Watanabe et al. [80]. Their samples were cold-rolled to $3 \mathrm{~mm}$ in thickness, solution-treated at $1303 \mathrm{~K}$ for $5 \mathrm{~h}$ in vacuum to ensure an initial structure of homogeneous single fcc phase before being quenched into cold water, and then annealed at 873,923 , and $973 \mathrm{~K}$ in vacuum. To simulate the final isothermal aging process, one needs to start from the nucleation of particles, and this can be readily tackled by using the Precipitation Module. Watanabe et al. [80] found that the shape of the particles could change from sphere to cuboid when the particles became large. However, they reported no data on the cubic factor. Therefore, we have ignored the morphological evolution in this simulation. The treatment of cuboids will be shown later in this section in our last case study, where experimental cubic factor data are available for precipitation hardening in another copper alloy.

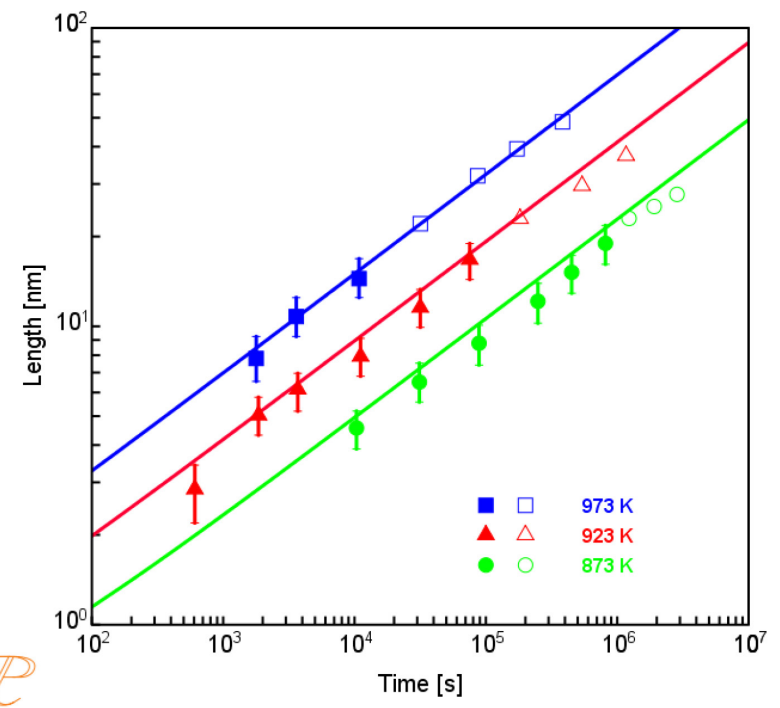

(a)

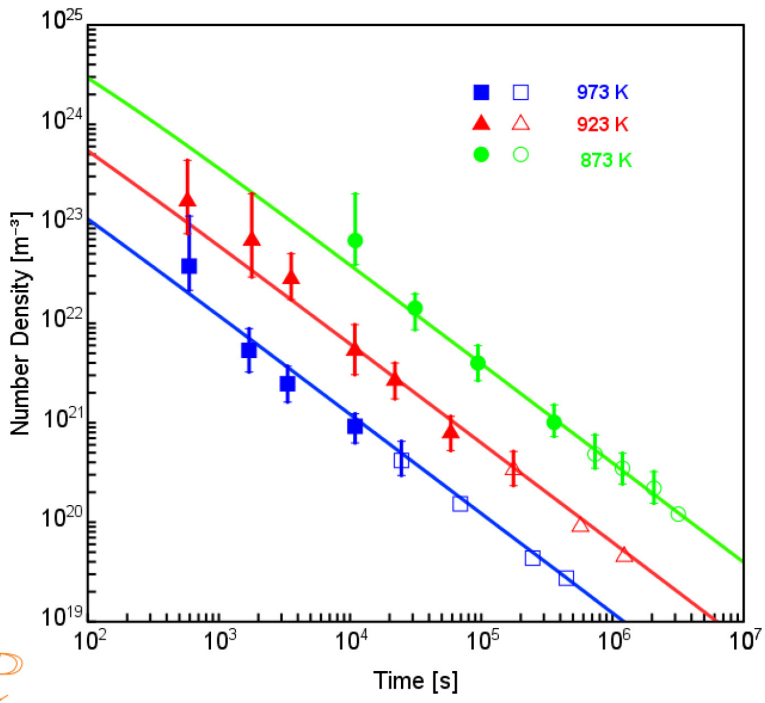

(b)

Figure 10 Comparison of the simulated (a) mean size and (b) number density of fcc Co-Fe precipitates in $\mathrm{Cu}-0.68$ at.\%Co-1.52 at.\%Fe alloy annealed at 973, 923, and $873 \mathrm{~K}$ with the experimental data [80]. The solid symbols are for spherical particles; and the open symbols are for cuboid particles, with the size of equivalent-volume sphere in (a).

In the present simulation, homogeneous nucleation is assumed on the basis of experimental information. The adopted value for the interfacial energy is $0.22 \mathrm{~J} / \mathrm{m}^{2}$, same as that reported by Watanabe et al. [80] for $973 \mathrm{~K}$. The simulated results on mean radius and number density are shown in Figure 10 together with the measurements. As can be easily seen, not only spherical but also cubic particles can be accounted for remarkably well. The normalized particle size distributions (PSD) for the $973 \mathrm{~K}$ precipitation at 0.5 and $48 \mathrm{~h}$ were also reported by Watanabe et al. [80] for this copper alloy. Our predictions are now compared with their measurements in Figure 11. The agreement is excellent considering the large uncertainty usually associated with the PSD experiments. 


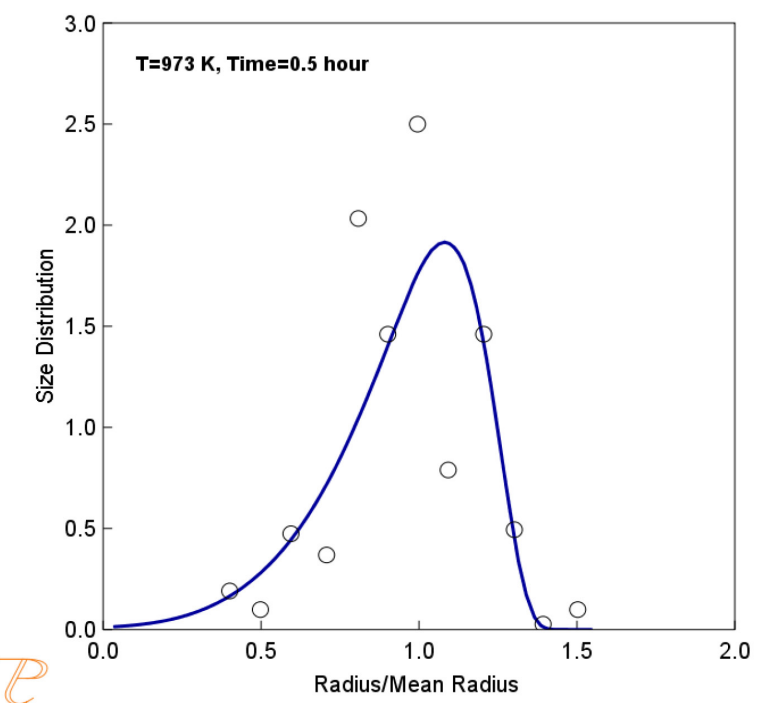

(a)

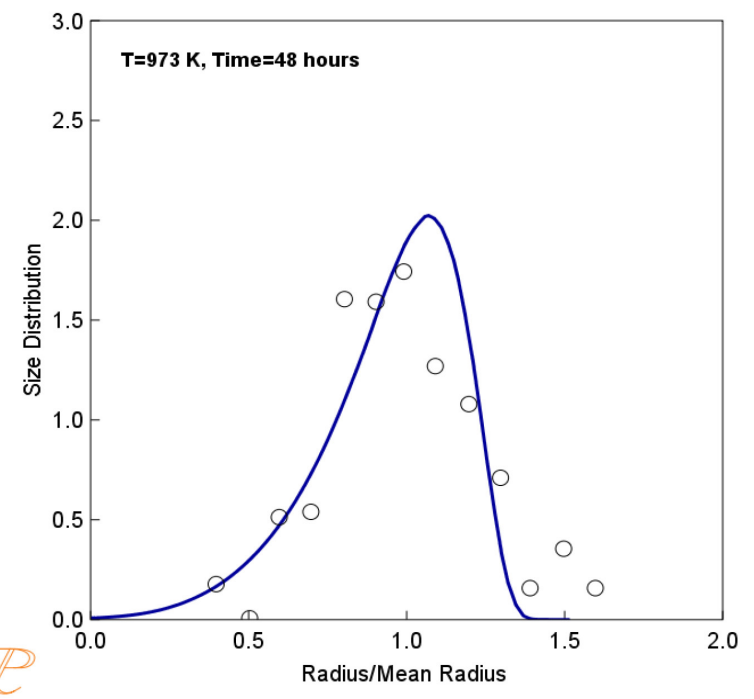

(b)

Figure 11 Comparison of the simulated particle size distribution of fcc Co-Fe precipitates in $\mathrm{Cu}-0.68$ at. $\% \mathrm{Co}-1.52$ at. $\% \mathrm{Fe}$ alloy annealed at $973 \mathrm{~K}$ for (a) $0.5 \mathrm{~h}$ and (b) $48 \mathrm{~h}$ with the experimental data [80].

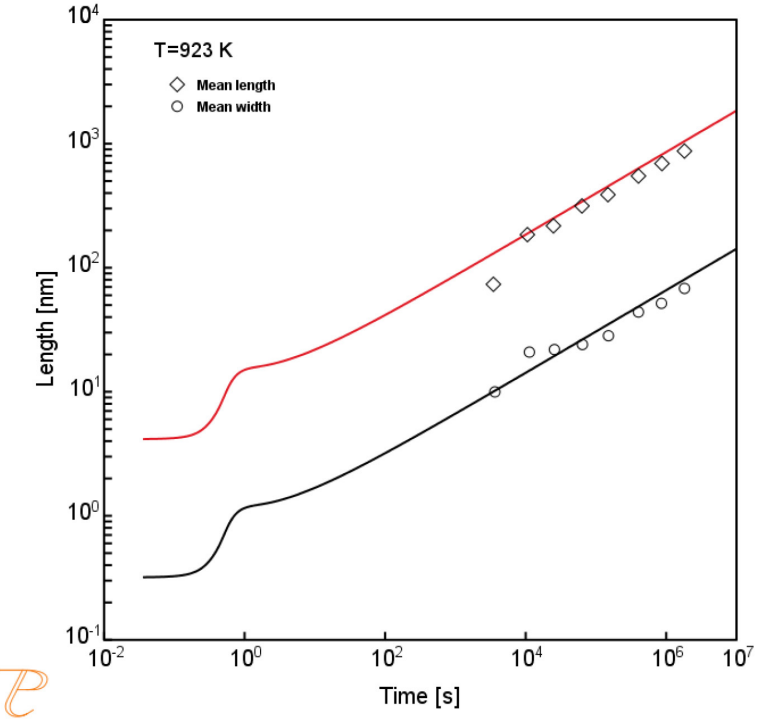

(a)

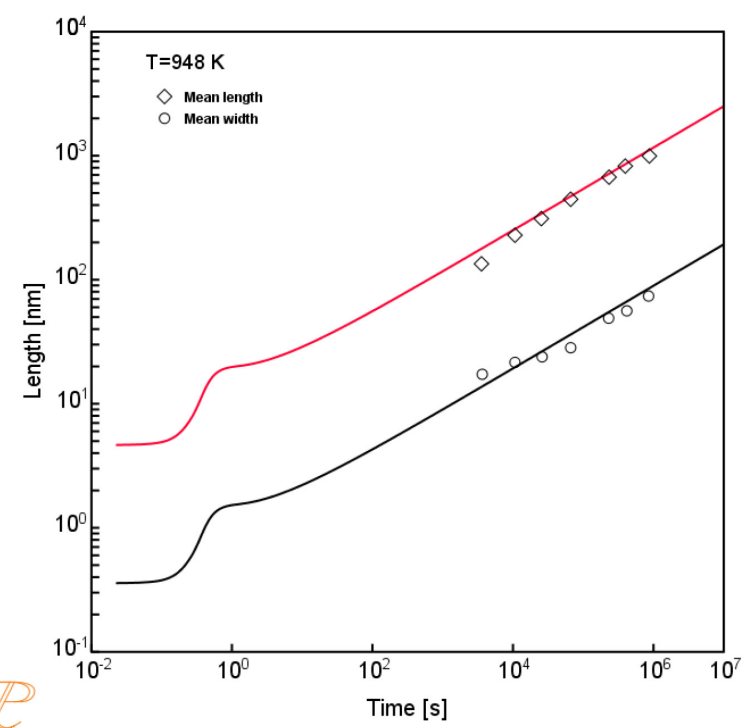

(b)

Figure 12 Simulated average length (red line) and width (black line) of rod-shaped precipitates with aging time for $\mathrm{Cu}-1.86 \mathrm{wt} . \% \mathrm{Ni}-0.45 \mathrm{wt} . \% \mathrm{Si}$ alloy at (a) $923 \mathrm{~K}$, and (b) $948 \mathrm{~K}$ compared with reported experimental data [82].

The $\mathrm{Cu}-\mathrm{Ni}$-Si alloy is a precipitation strengthening-type alloy and receives a lot of attention for its high strength, high electrical conductivity and excellent bending workability [81]. Watanabe and Monzen [82] experimentally determined precipitation behavior of the $\mathrm{Cu}-1.86 \mathrm{wt} . \% \mathrm{Ni}-0.45 \mathrm{wt} . \% \mathrm{Si}$ alloy at 923 and $948 \mathrm{~K}$. Their measurements show that the precipitate $\left(\mathrm{Ni}_{2} \mathrm{Si}\right)$ is a rod-shape one with an aspect ratio of 13. In the present simulation, the needle morphology is selected, and the aspect ratio is directly taken from the experimental measurements [82]. The model estimated interfacial energy $\left(0.22 \mathrm{~J} / \mathrm{m}^{2}\right)$ is used. The type of nucleation sites is set to ' $B u l k$ ', conforming to the experimentally observed homogenous nucleation. In Figure 12, a comparison has been made between the simulated mean length (red line) and mean width (black line) of the precipitates and their measured values. As can be seen, the simulation results agree with the measurements extremely well although there is nothing or any parameter that has been fitted. This fact suggests once we can create accurate thermodynamic and kinetic data pieces for the puzzle of phase transformations, they fall into place naturally. 
Fujii et al. [83] reported that $\mathrm{Co}-\mathrm{Cr}$ precipitates in a $\mathrm{Cu}$ matrix with shapes between a sphere and a cubic. The shape of cuboid morphology is determined by the competition between interfacial energy and elastic strain energy. The spherical-cuboidal transition during precipitation can be characterized by using a cubic factor $(\eta)$, which is defined as the ratio of the maximum radius to the minimum radius of the supersphere. In Fig. 13, the simulated cubic factors for the $\mathrm{Cu}-1.63 \mathrm{wt} . \% \mathrm{Co}-0.41 \mathrm{wt} . \% \mathrm{Cr}$ alloy annealed at $973 \mathrm{~K}$ for 48 hours is presented. During the simulation, homogenous nucleation has been assumed. The interfacial energy value $\left(0.38 \mathrm{~J} / \mathrm{m}^{2}\right)$ is taken from the model estimated value, and transformation strain is set to 'Calculate from molar volume' to obtain a purely dilatational strain. The default elastic constant values $\left(\mathrm{C}_{11}=168.4 \mathrm{GPa}, \mathrm{C}_{12}=121.4 \mathrm{GPa}, \mathrm{C}_{44}=75.4 \mathrm{GPa}\right)$ suggested by the software for copper alloys have been used. It is apparent that the shape of particles changes from sphere to cuboid with increasing size. The simulation results are compared with experimental data collected by Fujii et al. [83]. The prediction curve passes beautifully through the scattered experimental data points.

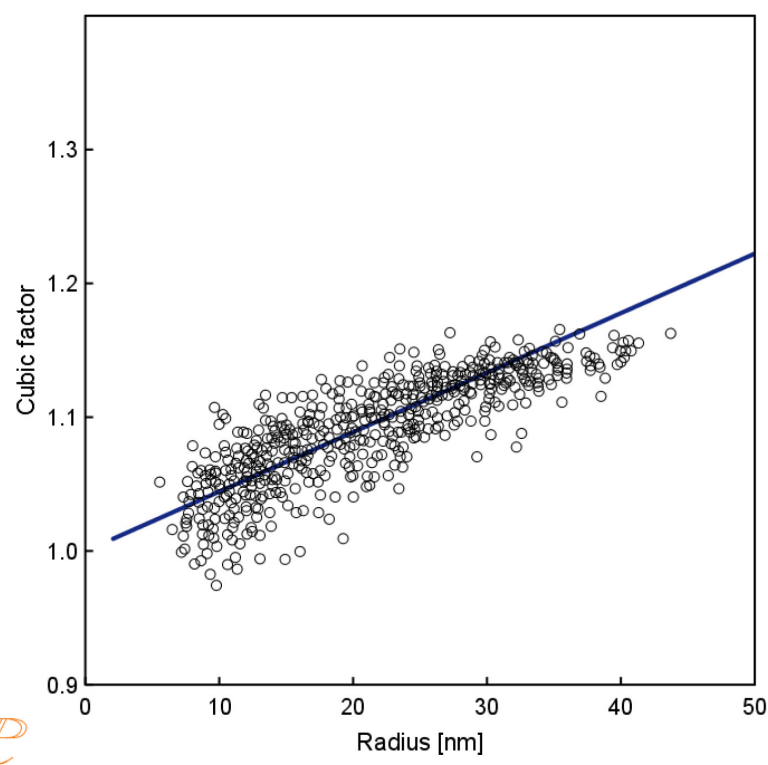

Figure13 Comparison of the presently simulated cubic factor distribution of precipitate in the $\mathrm{Cu}-1.63 \mathrm{wt} . \% \mathrm{Co}-0.41 \mathrm{wt} . \% \mathrm{Cr}$ alloy with experimental results [83]. The alloy was annealed at $973 \mathrm{~K}$ for 48 hours.

\section{Summary}

In order to simulate kinetics of diffusion controlled phase transformations in copper-based alloys, we have successfully developed a specific atomic mobility database (MOBCU) for this type of materials. MOBCU contains 29 elements $(\mathrm{Cu}, \mathrm{Ag}, \mathrm{Al}, \mathrm{As}, \mathrm{Au}, \mathrm{B}, \mathrm{Be}, \mathrm{Bi}, \mathrm{C}, \mathrm{Ca}, \mathrm{Cd}, \mathrm{Co}, \mathrm{Cr}, \mathrm{Fe}, \mathrm{Mg}$, $\mathrm{Mn}, \mathrm{Mo}, \mathrm{Nb}, \mathrm{Ni}, \mathrm{O}, \mathrm{P}, \mathrm{Pb}, \mathrm{Pt}, \mathrm{Se}, \mathrm{Si}, \mathrm{Sn}, \mathrm{Ti}, \mathrm{Zn}$ and $\mathrm{Zr}$ ) and the descriptions for both the liquid phase and the Fcc_A1 phase. The comparison between various calculated and experimental diffusion coefficients shows the high fidelity of this database in reproducing the experimental data for various diffusivities. The good agreement between the model-predicted and the measured concentration profiles for a variety of diffusion couples, especially for the ternary and quaternary diffusion couples, further validates the present atomic mobility database. Moreover, this mobility database has been applied to fulfil our primary goal of the present investigation. We have simulated the solidification and precipitation processes in several representative copper alloys by using the Diffusion Module and Precipitation Module in Thermo-Calc. It has been shown that this newly developed mobility database can be utilized to make rather accurate predictions of phase transformation kinetics. Future improvements and extensions of this atomic mobility database are expected to occur simultaneously with the compatible thermodynamic database. 


\section{References}

[1] L. Lu, Y. Shen, X. Chen, L. Qian, K. Lu, Ultrahigh strength and high electrical conductivity in Copper, Science 304 (2004) 422-426.

[2] Y. Tomioka, J. Miyake, A copper alloy development for leadframe, in Proceedings of 1995 Electronic Manufacturing Technology Symposium, Japan, 1995, pp. 433-436.

[3] M. Li, J.K. Heuer, J.F. Stubbins, D.J. Edwards, Fracture behavior of high-strength, high-conductivity copper alloys. J. Nucl. Mater. 283-287 (2000) 977-981.

[4] L. Kaufman, Computational thermodynamics and materials design, CALPHAD 25 (2001) 141-146.

[5] N. Saunders, A. P. Miodownik, CALPHAD: a comprehensive guide, Oxford, Pergamon, 1998.

[6] J. Bratberg, H. Mao, L. Kjellqvist, A. Engström, P. Mason, Q. Chen, The development and validation of a new thermodynamic database for Ni-Based alloys, in E. S. Huron, R. C. Reed, M. C. Hardy, M. J. Mills, R. E. Montero, P. D. Portella, J. Telesman (Eds.), Superalloys 2012, John Wiley \& Sons Inc., USA, 2012, pp. 803-812.

[7] L.J. Zhang, A. Markström, P. Mason, Y. Du, S. Liu, L. Kjellqvist, J. Bratberg, Q. Chen, A. Engström, TCAL1 and MOBAL2-The development and validation of new thermodynamic and mobility database for Aluminum alloys, in H. Weiland, A.D. Rollett, W.A. Cassada (Eds.) ICAA13 Pittsburgh, Springer, Cham, 2012, pp. 305-310.

[8] G.L. Xu, L.G. Zhang, L.B. Liu, Y. Du, F. Zhang, K. Xu, S.H. Liu, M. Tan, Z.P. Jin, Thermodynamic database of multi-component $\mathrm{Mg}$ alloys and its application to solidification and heat treatment, J. Magnesium Alloys 4 (2016) 249-264.

[9] H.H. Mao, H.L. Chen, Q. Chen, TCHEA1: A thermodynamic database not limited for "High Entropy' alloys, J. Phase Equilib. Diffus. 38 (2017) 353-368.

[10] J. Ågren, Diffusion in phases with several components and sublattice, J. Phys. Chem. Solids 43 (1982) 421-430.

[11] J. Ågren, Numerical treatment of diffusional reactions in multicomponent alloys, J. Phys. Chem. Solids 43 (1982) 385-391.

[12] Y. Du, L.J. Zhang, S.L. Cui, D.D. Zhao, D.D. Liu, W.B. Zhang, W.H. Sun, W.Q. Jie, Atomic mobilities and diffusivities in Al alloys, Sci. China Tech. Sci. 55 (2012) 306-328.

[13] Z.L. Bryan, P. Alieninov, I.S. Berglund, M.V. Manuel, A diffusion mobility database for magnesium alloy development, CALPHAD 48 (2015) 123-130.

[14] L.J. Zhang, Q. Chen, CALPHAD-type modeling of diffusion kinetics in multicomponent alloys, in A. Paul, S. Divinski (Eds.), Handbook of Solid State Diffusion-Diffusion Foundation and Techniques, Elsevier, 2017, pp. 321-362.

[15] Information on http://www.thermocalc.com/media/41192/tccu2_extended_info.pdf

[16] A. Borgenstam, A. Engström, L. Höglund, J. Ågren, DICTRA, a tool for simulation of diffusional transformations in alloys, J. Phase Equilib. 21 (2000) 269-280.

[17] J.O. Andersson, T. Helander, L. Höglund, P.F. Shi, B. Sundman, Thermo-Calc and DICTRA, computational tools for materials science, CALPHAD 26 (2002) 273-312.

[18] Q. Chen, J. Jeppsson, J. Ågren, Analytical treatment of diffusion during precipitate growth in multicomponent systems, Acta Mater. 56 (2008) 1890-1896.

[19] Q. Chen, K.S. Wu, G. Sterner, P. Mason, Modeling precipitation kinetics during heat treatment with Calphad-based tools, J. Mater. Eng. Perform. 23 (2014) 4193-4196. 
[20] L.J. Zhang, Y. Du, I. Steinbach, Q. Chen, B.Y. Huang, Diffusivities of an Al-Fe-Ni melt and their effects on the microstructure during solidification. Acta Mater. 58 (2010) 3664-3675.

[21] W.M. Chen, L.J. Zhang, Y. Du, B.Y. Huang, Viscosity and diffusivity in melts: from unary to multicomponent systems, Philos. Mag. 94 (2014) 1552-1577.

[22] W.M. Chen, L.J. Zhang, Y. Du, B.Y. Huang, Diffusivities and atomic mobilities of an Sn-Ag-Bi-Cu-Pb melt. Int. J. Mater. Res. 105 (2014) 827-839.

[23] R. Wang, W.M. Chen, L.J. Zhang, D.D. Liu, X. Li, Y. Du, Z.P. Jin, Diffusivities and atomic mobilities in the Al-Ce-Ni melts, J. Non-Cryst. Solids 379 (2013) 201-207.

[24] Y. Tang, L.J. Zhang, Y. Du, Diffusivities in liquid and fcc Al-Mg-Si alloys and their application to the simulation of solidification and dissolution processes, CALPHAD 49 (2015) 58-66.

[25] W.H. Sun, L.J. Zhang, M. Wei, Y. Du, B.Y. Huang, Effect of liquid diffusion coefficients on microstructure evolution during solidification of Al356 alloy, Trans. Nonferrous Met. Soc. China 23 (2013) 3722-3728.

[26] M. Wei, Y. Tang, L.J. Zhang, W.H. Sun, Y. Du, Phase Field simulation of microstructure evolution in industrial A2214 alloy during solidification. Metall. Mater. Trans. A 46 (2015) 3182-3191.

[27] H.X. Xu, W.M. Chen, L.J. Zhang, Y. Du, C.Y. Tang, High-throughput determination of the composition-dependent interdiffusivities in $\mathrm{Cu}$-rich fcc $\mathrm{Cu}-\mathrm{Ag}-\mathrm{Sn}$ alloys at $1073 \mathrm{~K}$, J. Alloys Compd. 644 (2015) 687-693.

[28] W.M. Chen, J. Zhong, L.J. Zhang, An augmented numerical inverse method for determining the composition-dependent interdiffusivities in alloy systems by using a single diffusion couple, Inter. MRS Commun. 6 (2016) 295-300.

[29] W.M. Chen, L.J. Zhang, High-Throughput determination of interdiffusion coefficients for Co-Cr-Fe-Mn-Ni High-Entropy alloys, J. Phase Equilib. Diff. 38 (2017) 457-465.

[30] J. Langer, A. Schwartz, Kinetics of nucleation in near-critical fluids, Phys. Rev. A 21 (1980) 948-958.

[31] R. Wagner, R. Kampmann, Homogeneous second phase precipitation, in P. Haasen (Ed.), Materials Science and Technology: A Comprehensive Treatment, John Wiley \& Sons Inc., Berlin, 1991, pp. 213-303.

[32] J.B. Brady, Reference frames and diffusion coefficients, Am. J. Sci. 275 (1975) 954-983.

[33] L.E. Trimble, D. Finn, A. Cosgarea, A mathematical analysis of diffusion coefficients in binary systems, Acta Metall. 13 (1965) 501-507.

[34] A. Einstein, On the movement of small particles suspend in stationary liquids required by the molecular-kinetic theory of heat, Ann. Physik. 17 (1905) 549-560.

[35] J.O. Andersson, J. Ågren, Models for numerical treatment of multicomponent diffusion in simple phases, J. Appl. Phys. 72 (1992) 1350-1355.

[36] B. Jönsson. Ferromagnetic ordering and diffusion of carbon and nitrogen in bcc Cr-Fe-Ni alloys, Z. Metallkd. 85 (1994) 498-501.

[37] O. Redlich, A.T. Kister, Algebraic representation of thermodynamic properties and the classification of solutions, Ind. Eng. Chem. 40 (1948) 345-348.

[38] F. Demmel, D. Szubrin, W.-C. Pilgrim, C. Morkel, Diffusion in liquid aluminum probed by quasielastic neutron scattering, Phys. Rev. B 84 (2011) 014307. 
[39] F. Kargl, H. Weis, T. Unruh, A. Meyer, Self-diffusion in liquid aluminum, J. Phys. Conf. Ser. 340 (2012) 012077.

[40] A. Meyer, Self-diffusion in liquid copper as seen by quasielastic neutron scattering, Phys, Rev. B. $81(2010) 012102$.

[41] E.S. Levin, V.N. Zamaraev, P.V. Sverdlovsk, Izvestiya. Akademii. Nauk. SSSR: Metally 2 (1976) 113.

[42] N.H. Nachtried, E. Fraga, C. Wahl, Self-diffusion of liquid zinc, J. Phys. Chem. 67 (1963) 2353-2355.

[43] W. Lange, W. Pippel, F. Bendel, Self-diffusion of liquid zinc, Z. Phys. Chem. 212 (1959) $238-240$.

[44] M.M.G. Alemany, L.J. Gallego, L.E. González, D. J. González, A molecular dynamics study of the transport coefficients of liquid transition and noble metals using effective pair potentials obtained from the embedded atom model, J. Chem. Phys., 113 (2000) 10410.

[45] A.S. Chauhan, R. Ravi, R.P. Chhabra, Self-diffusion in liquid metals, Chem. Phys. 252 (2000) 227-236.

[46] C. Jayaram, R. Ravi, R.P. Chhabra, Calculation of self-diffusion coefficients in liquid metals based on hard sphere diameters estimated from viscosity data, Chem. Phys. Lett. 341 (2001) $179-184$.

[47] A.Z.Z. Ahmed, G.M. Bhuiyan, Application of the EAM potentials to the study of atomic transport of liquid transition and noble metals, Int. J. Mod. Phys. B 16 (2002) 3837-3846.

[48] B. Szpunar, R.W. Smith, A molecular dynamics simulation of the diffusion of the solute (Au) and the self-diffusion of the solvent $(\mathrm{Cu})$ in a very dilute liquid $\mathrm{Cu}-\mathrm{Au}$ solution, J. Phys. Condens. Matter. 22 (2010) 035105.

[49] H.M. Lu, G. Li, Y.F. Zhu, Q. Jiang, Temperature dependence of self-diffusion coefficient in several liquid alkali metals, J. Non-Cryst. Solids 352 (2006) 2797-2800.

[50] J. Mei, J.W. Davenport, Molecular-dynamics study of self-diffusion in liquid transition metals, Phys. Rev. B 42 (1990) 9682.

[51] M. Dzugutov, A universal scaling law for atomic diffusion in condensed matter, Nature 381 (1996) 137-139.

[52] T. Iida, R. Guthrie, N. Tripathi, A model for accurate predictions of self-diffusivities in liquid metals, semimetals, and semiconductors, Metall. Mater. Trans. B 37 (2006) 559-564.

[53] T. Koishi, Y. Shirakawa, S. Tamaki, Simulation of shear viscosity in liquid metals, Comput. Mater. Sci. 6 (1996) 245-253.

[54] I. Yokoyama, Self-diffusion coefficient and its relation to properties of liquid metals: a hard-sphere description, Phys. B 271 (1999) 230-234.

[55] I. Yokoyama, T. Arai, Correlation entropy and its relation to properties of liquid iron, cobalt and nickel, J. Non-Cryst. Solids 293-295 (2001) 806-811.

[56] J. Brillo, S.M. Chathoth, M.M. Koza, A. Meyer, Liquid $\mathrm{Al}_{80} \mathrm{Cu}_{20}$ : Atomic diffusion and viscosity, Appl. Phys. Lett .93 (2008) 121905.

[57] B. Zhang, A. Griesche, A. Meyer, Diffusion in Al-Cu melts studied by time-resolved X-ray radiography, Phys. Rev. Lett. 104 (2010) 035902.

[58] T. Yamamura, T. Ejima, Diffusion of monovalent solutes in liquid copper and silver. J. Jpn. Inst. Met. 37 (1973) 901-907. 
[59] A. Griesche, S.M. Chathoth, M. Macht, G. Frohberg, M. Koza, A. Meyer, High Temp.-High Press. 37 (2008) 153-162.

[60] A.I. Pommrich, A. Meyer, D. Holland-Moritz, T. Unruh, Nickel self-diffusion in silicon-rich Si-Ni melts, Phys. Lett. 92 (2008) 241922.

[61] R. Resnick, R.W. Balluffi, Diffusion of zinc and copper in alpha and beta brasses, J. Met. 7 (1955) 1004-1010.

[62] M. Onishi, T. Shimozaki, T. Hayashida, M. Hirata, Interdiffusion and intrinsic diffusion-coefficients in alpha-solid solution of Cu-Zn system, J. Japan Inst. Metals 48 (1984) 890-895.

[63] T. Takahashi, M. Kato, Y. Minamino, T. Yamane, T. Azukizawa, T. Okamoto, M. Shimada, N. Ogawa, Effect of high pressure on interdiffusion in Cu-Zn alloys, Z. Metll. 75 (1984) 440-459.

[64] F.N. Rhines, R.F. Mehl, Rates of diffusion in the alpha solid solutions of copper, Trans. Am. Inst. Mining Met. Engrs. 128 (1938) 185-221.

[65] R.W. Balluffi, L.L. Seigle, Diffusion in bimetal vapor-solid couples, J. Appl. Phys. 25 (1954) 607-614

[66] H. Oikawa, K.J. Anusavice, R.T. DeHoff, A.G. Guy, Diffusion of $\mathrm{Zn}^{65}$ in Copper-rich solid solutions of the $\mathrm{Cu}-\mathrm{Ni}-\mathrm{Zn}$ system, Trans. ASM 61 (1968) 354-356.

[67] K.J. Anusavice, R.T. DeHoff, Diffusion of the tracers $\mathrm{Cu}^{67}, \mathrm{Ni}^{66}$, and $\mathrm{Zn}^{65}$ in copper-rich solid solutions in the system Cu-Ni-Zn, Metall. Trans. 3 (1972) 1278-1298.

[68] R.T. DeHoff, A.G. Guy, K.J. Anusavice, T.B. Lindemer, The diffusion of the tracer, ${ }^{65} \mathrm{Zn}$, in the copper-rich corner of the $\alpha$ solid solution in the system $\mathrm{Cu}-\mathrm{Ni}-\mathrm{Zn}$, Trans. TMS-AIME 236 (1966) 881-890.

[69] T. Takahashi, M. Kato, Interdiffusion in a-solid solutions of ternary $\mathrm{Cu}-\mathrm{Mn}-\mathrm{X}(\mathrm{X}=\mathrm{Al}, \mathrm{Ni}, \mathrm{Zn})$ alloys), Shindo Gijutsu Kenkyu Kaishi (in Japanese) 33 (1994) 88-101.

[70] S. D. Beattiea, J. R. Dahn, Combinatorial electrodeposition of ternary Cu-Sn-Zn alloys, J. Electrochem. Soc. 152 (2005) 542-548.

[71] L. Picincu, D. Pletcher. A. dan Smith, Electrochemistry of the SUCOPLATE® Electroplating Bath for the Deposition of a Cu-Zn-Sn Alloy, Part I: Commercial Bath, J. App. Electrochem. (2001) 387-394.

[72] T. Takahashi, M. Kato, Interdiffusion in solid solutions of the Cu-Zn-Sn system, J. Mater. Sci. 22 (1987) 3194-3202.

[73] Y.H. Sohn, M.A. Dayananda, A double-serpentine diffusion path for a ternary diffusion couple, Acta Mater. 48 (2000) 1427-1433.

[74] K.E. Kansky, M.A. Dayananda, Quaternary diffusion in the $\mathrm{Cu}-\mathrm{Ni}-\mathrm{Zn}-\mathrm{Mn}$ system at $775^{\circ} \mathrm{C}$, Metall. Trans. A 16 (1985) 1123-1132.

[75] W. Kurz, Solidification microstructure-processing maps: theory and application, Adv. Eng. Mater. 3 (2001) 443-452.

[76] B. Korojy, L. Ekbom, H. Fredriksson, Microsegregation and solidification shrinkage of copper-lead base alloys, Adv. Mater. Sci. Eng. 2009 (2009) 627937.

[77] T.P. Battle, Mathematical modelling of solute segregation in solidifying materials, Int. Mater. Rev. 37 (1992) 249-270.

[78] H. Fredriksson, U. Akerlind, Solidification and Crystallization Processing in metals and Alloys, John Wiley \& Sons, Chichester, West Sussex, 2012.

[79] Information on http://www.thermocalc.com/media/50243/release-notes_2017b.pdf 
[80] D. Watanabe, C. Watanabe, R. Monzen, Determination of the interface energies of spherical, cuboidal and octahedral face-centered cubic precipitates in $\mathrm{Cu}-\mathrm{Co}, \mathrm{Cu}-\mathrm{Co}-\mathrm{Fe}$ and $\mathrm{Cu}-\mathrm{Fe}$ alloys, Acta Metal. 57 (2009) 1899-1911.

[81] H. Fujiwara, A. Kamio, Effect of alloy composition on precipitation behavior in $\mathrm{Cu}-\mathrm{Ni}-\mathrm{Si}$ alloys, J. Jpn. Inst. Metal. 62 (1998) 3011309.

[82] C. Watanabe, R. Monzen, Coarsening of $\delta$-Ni2Si precipitates in a Cu-Ni-Si alloy, J. Mater. Sci. 46 (2011) 4327-4335.

[83] T. Fujii, T. Tamura, M. Kato, S. Onaka, Size-dependent equilibrium shape of Co-Cr particles in $\mathrm{Cu}$, Microsc. Microanal. 8 (2002) 1434-1435. 